\title{
Antifungal and Antibiofilm Activities of B-Type Oligomeric Procyanidins From Commiphora leptophloeos Used Alone or in Combination With Fluconazole Against Candida spp.
}

\section{OPEN ACCESS}

Edited by:

Miguel Cacho Teixeira

University of Lisbon, Portugal

Reviewed by:

Natália Cruz-Martins,

Universidade do Porto, Portugal

Hamed Fakhim,

Urmia University of Medical Sciences,

Afsane Vaezi,

Mazandaran University of Medical

Sciences, Iran

${ }^{*}$ Correspondence:

Silvana Maria Zucolotto

silvanazucolotto@ufrnnet.br;

szucolotto@hotmail.com

Specialty section:

This article was submitted to Antimicrobials, Resistance

and Chemotherapy,

a section of the journal

Frontiers in Microbiology

Received: 01 October 2020

Accepted: 04 January 2021

Published: 22 February 2021

Citation:

Dantas-Medeiros R, Zanatta AC

de Souza LBFC, Fernandes JM,

Amorim-Carmo B, Torres-Rêgo M, Fernandes-Pedrosa MF, Vilegas W,

Araújo TAS, Michel S, Grougnet R,

Chaves GM and Zucolotto SM (2021) Antifungal and Antibiofilm Activities of

B-Type Oligomeric Procyanidins From

Commiphora leptophloeos Used

Alone or in Combination With

Fluconazole Against Candida spp.

Front. Microbiol. 12:613155.

doi: 10.3389/fmicb.2021.613155
Renato Dantas-Medeiros ${ }^{1}$, Ana Caroline Zanatta ${ }^{2,3}$, Luanda Bárbara Ferreira Canário de Souza ${ }^{4}$, Júlia Morais Fernandes ${ }^{1}$, Bruno Amorim-Carmo5 ${ }^{5}$, Manoela Torres-Rêgo ${ }^{5}$, Matheus de Freitas Fernandes-Pedrosa ${ }^{5}$, Wagner Vilegas ${ }^{3}$, Thiago Antǒnio de Sousa Araújo ${ }^{6}$, Sylvie Michel7, Raphaël Grougnet ${ }^{7}$, Guilherme Maranhão Chaves ${ }^{4}$ and Silvana Maria Zucolotto ${ }^{1 *}$

'Laboratory of Pharmacognosy, Department of Pharmaceutical Sciences, Faculty of Pharmacy, Federal University of Rio Grande do Norte, Natal, Brazil, ${ }^{2}$ Laboratory of Bioprospecting of Natural Products, São Paulo State University (UNESP), São Paulo, Brazil, ${ }^{3}$ Laboratory of Phytochemistry, Institute of Chemistry, São Paulo State University (UNESP), São Paulo, Brazil, ${ }^{4}$ Laboratory of Medical and Molecular Mycology, Department of Clinical and Toxicological Analyses, Federal University of Rio Grande do Norte, Natal, Brazil, ${ }^{5}$ Laboratory of Technology and Pharmaceutical Biotechnology (Tecbiofar), Faculty of Pharmacy, Federal University of Rio Grande do Norte, Natal, Brazil, ${ }^{6}$ Department of Health, University Center of Maurício de Nassau, Recife, Brazil, ' Laboratory of Pharmacognosy, Faculty of Pharmacy, University Paris Descartes, Paris, France

Commiphora leptophloeos (Burseraceae) is a medicinal plant native to Brazil which is popularly used for treating oral and vaginal infections. There has been no scientific evidence pointing to its efficacy in the treatment of these infections. Thus, this study sought to investigate the cytotoxic, antifungal, and antibiofilm activity of $C$. leptophloeos against Candida spp. and to isolate, identify, and quantify the content of B-type oligomeric procyanidins (BDP) in the extract of $C$. leptophloeos stem bark. The extract and the $n$-butanol fraction were obtained by maceration and liquid-liquid partition, respectively. Phytochemical analysis performed by HPLC-PDA/ELSD and FIA-ESI-ITMS/MS allowed the identification and quantification of BDP in the samples. The application of centrifugal partition chromatography helped isolate BDP, which was identified by ${ }^{1} \mathrm{H}$ NMR and MS analyses. Candida spp. reference strains and clinical isolates (including fluconazole-resistant strains) derived from the blood cultures of candidemic patients and the vaginal secretion of patients with vulvovaginal candidiasis were used for evaluating the antifungal and antibiofilm effects. Minimal inhibitory concentration (MIC) and minimal fungicidal concentration (MFC) were determined by the microdilution technique, and biofilm inhibition was evaluated through crystal violet and XTT assays. The combined action of BDP with fluconazole was determined by the checkerboard method. The extract, the $n$-butanol fraction, and the BDP exhibited antifungal activity with MIC values ranging from 312.5 to $2500 \mu \mathrm{g} / \mathrm{mL}$ and were found to significantly reduce the biofilm formed in all the Candida strains investigated. 
BDP showed a fungicidal potential against strains of Candida spp. (especially against fluconazole-resistant strains), with MIC and MFC values ranging from 156.2 to 2500 $\mu \mathrm{g} / \mathrm{mL}$. In addition, the combined application of BDP and fluconazole produced synergistic antifungal effects against resistant Candida spp. $(\mathrm{FICl}=0.31-1.5)$. The cytotoxic properties of the samples evaluated in human erythrocytes through hemolytic test did not show hemolytic activity under active concentrations. The findings of the study show that $C$. leptophloeos has antifungal and antibiofilm potential but does not cause toxicity in human erythrocytes. Finally, BDP, which was isolated for the first time in C. leptophloeos, was found to exhibit antifungal effect against Candida spp. either when applied alone or in combination with fluconazole.

Keywords: Burseraceae, fungal infections, biofilm, resistance, herbal drug, natural antifungal, imburana

\section{INTRODUCTION}

Several microorganisms are part of the normal human microbiota, and these include the fungi from the Candida genus. Sixty five percent of Candida spp. are able to grow at temperatures below $37^{\circ} \mathrm{C}$; this facilitates the maintenance of their commensal state in the human host (Azzam et al., 2020). However, complex changes in microbial communities may cause various disorders, such as opportunistic fungal infections (Zelante et al., 2020). Candidiasis is the name given to a broad range of infections caused by the Candida species (Bonifácio et al., 2019). It is worth noting that Candida spp. have been found to be responsible for several fungal infections, such as oral and vulvovaginal candidiasis, skin infections, and onychomycosis; these infections may occur even in immunocompetent hosts, when predisposing factors are present (Fakhim et al., 2020).

Candidemia is a bloodstream infection caused by Candida spp.; this infection has been found to have a high mortality rate (35-75\%) which varies between regions and countries (Kaur and Chakrabarti, 2017; Fakhim et al., 2020). Among the Candida species, Candida albicans has been found to be the most prevalent species, responsible for about $80-90 \%$ of the cases involving Candidemia (Robbins et al., 2017). Although C. albicans is the most virulent and isolated species from the bloodstream of hospitalized patients, in recent years, studies published have pointed to a noticeable increase in the occurrence of infections caused by clinically relevant non-C. albicans Candida (NCAC) species, such as Candida tropicalis, Candida dubliniensis, Candida krusei, Candida glabrata, and Candida parapsilosis (Biswal et al., 2017; Banerjee et al., 2019).

The ability to form biofilms is one of the main virulence factors of Candida spp., particularly in C. albicans (Deorukhkar and Saini, 2016). Biofilms are communities of microorganisms attached to biotic or abiotic surfaces and which are surrounded by a matrix of polymeric extracellular substances that are difficult to eliminate (Sherry et al., 2017). The matrix protects fungal cells, preventing the penetration of antifungal drugs and the attack of phagocytic cells; this impairs the successful treatment of candidemia, specifically in those patients harboring a central venous catheter (Souza et al., 2018).
Currently, the main antifungal drugs commercially available are azoles, polyenes, echinocandins, and nucleoside analogs. Although there appears to be a reasonable number of antifungal drugs in the market, very few of these drugs, including amphotericin B and echinocandins, are effective against fungal infections associated with biofilm formation (Sherry et al., 2017; De Cássia Orlandi Sardi et al., 2018). In addition, these antifungal drugs have been found to have some limitations, which include increased antifungal resistance (mainly due to emerging Candida species), high costs, and high degree of toxicity in humans (Colombo et al., 2017; Spivak and Hanson, 2018). The emergence of multidrug-resistant fungi (for instance, Candida auris) makes the available therapeutic arsenal for the treatment of the infection even more limited (Nett, 2019). Other Candida species, such as Candida glabrata, Candida krusei, Candida lusitaniae, Candida kefyr, Yarrowia (Candida) lypolitica, and Candida rugose, have also been found to exhibit multidrug resistance (Colombo et al., 2017). New treatments which involve the combined application of antifungal drugs with synergistic effects have been shown to be a promising alternative to overcome the fungal resistance to current antifungal drugs (Fakhim et al., 2017). The interaction between micafungin and voriconazole has shown synergistic activity against multidrug-resistant $C$. auris (Fakhim et al., 2017). Also, the combined use of fluconazole and plant extracts has been found to enhance the ability of fluconazole to inhibit the expression of virulence factors of Candida spp. (Morais-Braga et al., 2016).

In this context, the discovery of new therapeutic agents that are highly efficient for the treatment of emerging opportunistic fungal infections is, undoubtedly, of great clinical relevance (Campoy and Adrio, 2017; Diba et al., 2018). The urgent need for the search of new antifungal drugs provides an impetus for the research and exploration of novel therapeutic alternatives from different natural sources (Sardi et al., 2013). Medicinal plants for the treatment of fungal infections are found to be highly promising in the sense that they have significant antimicrobial activity (either acting alone or in combination with antifungal drugs) and low degrees of toxicity, in addition to being less costly (Silva-Rocha et al., 2017).

Commiphora leptophloeos (Mart.) J.B. Gillett (Burseraceae) species is a medicinal plant native to the caatinga biome of 
the northeastern region of Brazil; the plant species is popularly known as "imburana" or "imburana-de-cambão." The stem bark of C. leptophloeos is widely used in traditional medicine for topical treatment of oral and vaginal infections, wounds, and inflammation-related problems (Agra et al., 2007; Cartaxo et al., 2010; Macedo et al., 2018). To date, few studies published in the literature have investigated the phytochemical and pharmacological properties of the stem bark of C. leptophloeos. Most non-clinical studies published in the literature have been mainly confined to investigating the antibacterial and antibiofilm activities, as well as the chemical composition of C. leptophloeos; these studies have reported the presence of phenolic acids, $\mathrm{O}$ - and $\mathrm{C}$-glycosylated flavonoids, lignans, and A- and B-type polymeric proanthocyanidins in C. leptophloeos, where the identified compounds have been related to therapeutic activities of the plant species (Trentin et al., 2013; Pereira et al., 2017; Da Silva et al., 2019; Dantas-Medeiros et al., 2021).

Considering the importance of C. leptophloeos in traditional medicine, coupled with the lack of scientific studies on this plant species, the present work sought to investigate the cytotoxicity and antifungal and antibiofilm activities of B-type oligomeric procyanidins from Commiphora leptophloeos alone or in combination with fluconazole against Candida spp. The study also aimed to isolate, characterize, and quantify the active compounds present in the stem bark of C. leptophloeos.

\section{MATERIALS AND METHODS}

\section{Chemicals and Reagents}

HPLC-grade acetonitrile and formic acid were acquired from J. T. Baker (Brazil) and LC-MS grade methanol (from Chromasolv) was used as mobile-phase components in the chromatographic analysis. Deuterated solvents were acquired from Euriso-Top (Saint Aubin, France). Folin-Ciocalteu reagent, Triton X-100, Yeast Nitrogen Base medium (YNB), D-glucose monohydrated, XTT/menadione, and fluconazole were purchased from SigmaAldrich (St. Louis, Missouri, United States of America). Mueller-Hinton medium was acquired from HiMedia (Mumbai, Maharashtra, India). Sabouraud Dextrose Agar (SDA) was acquired from Basingstoke, Hampshire, United Kingdom. RPMI 1640 culture medium (Roswell Park Memorial Institute) was acquired from Angus buffers and Biochemical, Niagara Falls, New York, United States of America. All other reagents and solvents used in the experiments were of analytical grade. The water used was purified by Milli-Q reverse osmosis (Millipore).

\section{Plant Material}

Commiphora leptophloeos stem barks were collected in the community of Carão, Altinho $\left(8^{\circ} 29^{\prime} 32^{\prime \prime}\right.$ latitude and $36^{\circ}$ $03^{\prime}$ 03" longitude), Pernambuco, in the northeastern region of Brazil, in July 2016. The vegetal material was identified in the Geraldo Mariz Herbarium of the Federal University of Pernambuco (UFPE) (number 46.191). Permission to collect the material was issued by the Brazilian Authorization and Biodiversity Information System (SISBIO) (process number 35017). The National System for the Management of Genetic
Heritage and Associated Traditional Knowledge (SISGEN) gave the authorization for the conduct of the scientific research (process number A618873).

\section{Preparation of Hydroethanolic Extract and Procyanidins-Rich Fraction}

The stem bark was dried in a circulating air oven (temperature below $45^{\circ} \mathrm{C}$ ), and then ground in a knife mill. An amount of $200 \mathrm{~g}$ of the powder material was extracted with ethanol: water (70:30, $\mathrm{v} / \mathrm{v}$ ) by maceration for $48 \mathrm{~h}$ in a plant/solvent proportion of 1:10 $(\mathrm{w} / \mathrm{v})$ (extract 1$)$. The extract was filtered through Whatman ${ }^{\mathrm{TM}}$ paper number 1 and the same vegetal material was extracted (remaceration) under the same conditions previously described (extract 2). Both extracts were combined and concentrated under reduced pressure using a rotary evaporator (temperature below $35^{\circ} \mathrm{C}$ ) (Buchi-Model V-700, Altendorfer Str. 3, Essen, Germany) in order to remove the organic solvent; this yielded the hydroethanolic extract of Commiphora leptophloeos (named HECL). The extract was frozen and lyophilized at $200 \mathrm{mT}$ for 72 h at $-60^{\circ} \mathrm{C}$ (Model 101, Liotop ${ }^{\circledR}$, São Carlos, São Paulo, Brazil).

The procyanidins-rich fraction was obtained based on the technique proposed by Rohr et al. (2000) with some modifications. In brief, $100 \mathrm{~g}$ of the HECL was subjected to liquid-liquid extraction with solvents of increasing polarity (dichloromethane, ethyl acetate, and $n$-butanol) and water, in the ratio of 2:1 (extract: solvent, v/v), to obtain the oligomeric procyanidins-rich $n$-butanolic fraction (BF). For each solvent, three partitions were made, each one starting from 200 of extract to $100 \mathrm{~mL}$ of organic solvent $(3 \times 100 \mathrm{~mL})$. The BF was concentrated using a rotary evaporator (temperature below $35^{\circ} \mathrm{C}$ ); the fraction was then lyophilized and stored at $-20^{\circ} \mathrm{C}$. The HECL and BF amounted to 25.6 and $12.5 \mathrm{~g}$, respectively.

\section{Pretreatment of Sample}

The HECL and BF were treated using solid phase extraction (SPE; Chromabond ${ }^{\circledR}, 45 \mu \mathrm{m}, 500 \mathrm{mg}, 6 \mathrm{~mL}$ ). The cartridges were pre-activated with $\mathrm{MeOH}(3.0 \mathrm{~mL})$ and equilibrated with $\mathrm{H}_{2} \mathrm{O}$ $(3.0 \mathrm{~mL})$. An amount of $50 \mathrm{mg}$ of the dry extract was dissolved in $\mathrm{EtOH} / \mathrm{H}_{2} \mathrm{O}(85: 15 \mathrm{v} / \mathrm{v})$, loaded to a C-18 cartridge, and eluted sequentially with $3 \mathrm{~mL}$ of the same mobile phase. The solvent was dried under $\mathrm{N}_{2}$ atmosphere.

\section{Phytochemical Characterization by Mass Experiments}

The samples were separately analyzed through direct injection by flow injection-electrospray ionization-ion trap-tandem mass spectrometry (FIA-ESI-IT-MS/MS) technique. All the samples were diluted in pure methanol to a concentration of $10 \mathrm{ppm}$ for HECL and BF, and $2 \mathrm{ppm}$ for BDP. The MS analysis was conducted using a Thermo Scientific LTQ XL linear ion trap mass spectrometer (acquired from Thermo-San Jose, California, United States of America) equipped with an electrospray ionization (ESI) source in negative mode. The following was applied for the analysis: a fused-silica capillary tube at $280^{\circ} \mathrm{C}$, with spray voltage of $5.00 \mathrm{kV}$, capillary voltage of $-47 \mathrm{~V}$, tube lens of $-226 \mathrm{~V}$, and flow rate of $5.0 \mu \mathrm{L} / \mathrm{min}$. The working range 
applied for the full scan analysis varied from $m / z 150-1,500$. The systems were pre-selected through a full scanning of the MS to acquire data related to the ions within the established $\mathrm{m} / \mathrm{z}$ range. Thereafter, MS/MS experiments were performed based on the data for the precursor ions of interest with $30 \%$ of collision energy and an activation time of $30 \mathrm{~ms}$. The data were acquired and processed using the Xcalibur ${ }^{\mathrm{TM}}$ version 1.3 software (from Thermo Finigan, San Jose, California, United States of America).

\section{Centrifugal Partition Chromatography (CPC) Purification Procedure for Isolation of B-Type Dimeric Procyanidin (BDP)}

\section{Distribution Coefficient (K) Estimation and Solvents System Selection}

The solvents system was selected based on an estimation of the distribution coefficient $(\mathrm{K})$, defined as the ratio of concentrations of the targeted compounds between the two non-miscible phases (Hopmann et al., 2012). K was evaluated by the shakeflask method and thin layer chromatography (TLC) under the following conditions: small amounts (about $2 \mathrm{mg}$ ) of the $\mathrm{BF}$ were added to the previously equilibrated biphasic solvents systems in test vials and were vigorously shaken for $2 \mathrm{~min}$. After decantation, TLC analysis was performed under ultravioletvisible light (UV) and sprayed with a solution of sulfuric vanillin; the mobile phase system obtained comprised the following: $\mathrm{AcOEt} / \mathrm{MeOH} / \mathrm{C}_{3} \mathrm{H}_{6} \mathrm{O} / \mathrm{H}_{2} \mathrm{O}$ (0.1:1.8:1.1:0.5 v/v/v/v).

\section{Isolation of B-Type Dimeric Procyanidin}

The BF was subjected to preparative analysis by CPC. The CPC analysis was performed using a double rotor CPC- $250+1,000$ B apparatus (Gilson Purification SAS, Saint-Avé, France) with an inbuilt quaternary high-pressure gradient pump and 1,953 ovoid twin-cell technology cells for the $250 \mathrm{~mL}$ column. The AcOEt/MeOH/C ${ }_{3} \mathrm{H}_{6} \mathrm{O} / \mathrm{H}_{2} \mathrm{O}$ (0.1:1.8:1.1:0.5 v/v/v/v) system was prepared in a separation funnel, vigorously shaken, and left idle at room temperature $\left(25^{\circ} \mathrm{C}\right)$ until the separation of the phases. $\mathrm{CPC}$ was operated in ascending mode at room temperature with rotational speed set at 1,200 rpm. The mobile phase was pumped through the column at the desired flow rate of $20 \mathrm{~mL} / \mathrm{min}$.

A sample containing $6.0 \mathrm{~g}$ of BF was dissolved in $45 \mathrm{~mL}$ of biphasic solvents system (35 mL of upper phase and $15 \mathrm{~mL}$ of lower phase) and injected through a $50 \mathrm{~mL}$ loop. This experiment yielded 25 sub-fractions (SF) which were evaluated by TLC using the same mobile phase described above. Finally, an analysis was conducted aimed at verifying whether the SF-16 was a pure compound; the analysis was carried out using proton nuclear magnetic resonance $\left({ }^{1} \mathrm{H}\right.$ NMR) and mass spectrometry (MS). After the analysis, the compound was identified as B-type dimeric procyanidin (named BDP).

\section{Nuclear Magnetic Resonance Analysis}

The ${ }^{1} \mathrm{H}$ NMR spectra of the isolated compound were recorded at $400 \mathrm{MHz}$ with the aid of a Bruker Avance III 400 spectrometer, using Bruker pulse programs. NMR Fourier transform, integration, and peak picking analyses were conducted using Bruker TopSpin software version 3.2. Chemical shifts were reported in ppm and coupling constants $(J)$ in Hertz. The isolated compound was dissolved in suitable deuterated methanol.

\section{Quantification of B-Type Oligomeric Procyanidins by Liquid Chromatography Analyses}

To conduct the high-performance liquid chromatographyphotodiode array/evaporative light scattering detection (HPLCPDA/ELSD) analyses, the following equipment was employed: JASCO $^{\circledR}$ model ELS-2040/2041 HPLC and JASCO ${ }^{\circledR}$ automatic pump model of quaternary pump, coupled to photodiode detection (PDA) and evaporative light scattering detector (ELSD). LC separations were performed using a C-18 column (Thermo Scientific ${ }^{\circledR} \mathrm{RO}, 250 \times 4.6 \mathrm{~mm}, 5 \mu \mathrm{m}$ particle size). The mobile phase-which was composed of water (solvent A) and acetonitrile (solvent B), both acidified with $0.1 \%$ formic acid-was used for the samples elution. The optimized gradient method was employed: $10-20 \% \mathrm{~B}, 0-7 \mathrm{~min} ; 20 \% \mathrm{~B}, 7-25 \mathrm{~min}$, and $20-60 \%$ $\mathrm{B}, 25-45 \mathrm{~min}$. The flow rate of $0.8 \mathrm{~mL} / \mathrm{min}$ and injection volume of $10 \mu \mathrm{L}$ were applied. The UV-PDA detector was programmed at the wavelength of $150-550 \mathrm{~nm}$ and the chromatograms were plotted at $280 \mathrm{~nm}$. The ELSD was operated with a drift tube temperature of $40^{\circ} \mathrm{C}$ and nebulizer gas pressure of 3.5 bar. The HECL and BDP dried samples were re-suspended in pure $\mathrm{MeOH}$ in a concentration of 10 and $3 \mathrm{mg} / \mathrm{mL}$, respectively, and filtered through a Millex ${ }^{\circledR}$ PTFE filter $(0.22 \mu \mathrm{m}, 25 \mathrm{~mm})$. The analysis of each sample was performed in triplicate. Chromatographic data acquisition and processing were performed using the ChromNAV software (Chromatec ${ }^{\circledR}$ ).

The quantification technique applied here was conducted in line with the Brazilian legislation no. 166, promulgated on July 24, 2017 (Anvisa, 2017) and under the regulatory guidelines Q2 (R1) of the International Conference on Harmonization of Technical Requirements for Registration of Pharmaceuticals for Human Use (ICH) (Singh, 2015). For the quantification analysis, the following parameters were evaluated: specificity, selectivity, calibration curve, linearity, limit of detection (LOD), limit of quantification (LOQ), and precision. The specificity of the method was conducted by co-injection of the BDP (purity $>95 \%$ HPLC) and the extract in order to evaluate the increase in peak area. The index of similarity between the UV spectrum of the standard (BDP) and the UV spectrum of each peak in the chromatographic profile was calculated in order to verify the different compounds with similar UV absorption to the BDP in the extract (HECL). Finally, the HPLC-ELSD analysis was conducted in order to quantify all the peaks observed in the extract. The selectivity of the method was determined by analyzing and comparing the chromatographic data (UV spectrum, retention time, and peak spectral purity) of HECL with the data obtained for the BDP in triplicate.

The BDP analytical curve was constructed using five concentration levels $(250,500,1,000,1,250$, and 1,500 $\mu \mathrm{g} / \mathrm{mL})$. Each concentration level was analyzed in triplicate. The average of the chromatographic peak areas in the ELSD chromatogram was interpolated as a function of known concentrations of BDP; 
this was done in order to establish the linear regression equation and the correlation coefficients. The limit of detection (LOD) and the limit of quantification (LOQ) were determined based on signal-to-noise ratios of 3.3:1 and 10:1, respectively. The external standard method was applied in order to quantify each peak of the extract. The peaks $1-5$ of the extract were quantified using the BDP calibration curve.

\section{Determination of Total Polyphenolic Content (TPC)}

The total polyphenol content (TPC) of HECL and BF was estimated based on the Folin-Ciocalteu (F-C) reagent method, as previously reported, with slight modifications (Attard, 2013). In a 96-well plate, an amount of $25 \mu \mathrm{L}$ of sample solution at $2 \mathrm{mg} / \mathrm{mL}$ was mixed with $125 \mu \mathrm{L}$ of F-C reagent freshly diluted to 1:10 (v/v) with distilled $\mathrm{H}_{2} \mathrm{O}$. After $5 \mathrm{~min}$, an amount of $100 \mu \mathrm{L}$ of the solution was mixed with $100 \mu \mathrm{L}$ of a $7.5 \% \mathrm{Na}_{2} \mathrm{CO}_{3}$ solution; the mixture was then left for $30 \mathrm{~min}$ in the dark and the absorbance was measured in a microplate reader (Epoch-Biotek ${ }^{\circledR}$, Winooski, Vermont, United States of America) at $765 \mathrm{~nm}$. The respective standard curves of gallic acid $(1.25,2.5,5,10,20,40,60$, and 80 $\mu \mathrm{g} / \mathrm{mL}$ ) and the blank (replacing F-C reagent with $125 \mu \mathrm{L} \mathrm{H}_{2} \mathrm{O}$ ) were constructed simultaneously. Thereafter, the total phenol content was calculated as mg of gallic acid (EAG) equivalent per $\mathrm{g}$ of the sample (mg of EAG/g of sample). For each sample, the analysis was performed in triplicate $(n=3)$.

\section{Toxicity Study \\ In vitro Hemolytic Activity Assay}

The toxicity of HECL, BF, and BDP was evaluated by hemolytic assay using healthy human donor blood, after obtaining written informed consent and approval from the Research Ethics Committee of the Onofre Lopes University HospitalHUOL/UFRN/Brazil (process number 3.676.695). The assay employed was based on the methodology described by AmorimCarmo et al. (2019), where an erythrocyte suspension (2\% v/v) was washed 3 times in $0.9 \%$ saline $(\mathrm{pH} 7.4)$ and centrifuged at $1,500 \mathrm{rpm}$ for $10 \mathrm{~min}$. Human erythrocytes were incubated for $1 \mathrm{~h}$ at $37^{\circ} \mathrm{C}$ with the HECL, BF, or BDP at different concentrations $(19.5-625 \mu \mathrm{g} / \mathrm{mL})$ and centrifuged at $1,500 \mathrm{rpm}$ for $10 \mathrm{~min}$. The content of hemoglobin present in the supernatant was quantified at $540 \mathrm{~nm}$ using a microplate reader. The positive control of the assay was $1 \%(\mathrm{v} / \mathrm{v})$ Triton X-100 solution (100\% cell lysis) and the negative control applied was $0.9 \%$ saline solution ( $0 \%$ cell lysis). The values were expressed as mean \pm S.D. $(n=3)$.

\section{Antifungal and Antibiofilm Activities}

\section{Selection of Microorganisms and Culture Conditions}

In order to investigate the antifungal, antibiofilm, and synergistic effects of the extract, nine clinical isolates of Candida spp. were obtained from the blood cultures of patients with candidemia, as well as from vaginal secretion of patients with vulvovaginal candidiasis. The research project was approved by the Local Research Ethics Committee ("Comitê de Ética em Pesquisa da Liga Norte Riograndense Contra o Câncer”), under the protocol number 042/042/2012. Written consent from the patients was not required because of the observational nature of the study, coupled with the fact that no clinical conditions and/or demographic data of patients are displayed in the manuscript.

The bloodstream isolates, namely, C. tropicalis LMMM195, C. tropicalis LMMM447, C. krusei LMMM249, C. glabrata LMMM704, C. parapsilosis LMMM83, and C. parapsilosis LMMM85, along with C. albicans strains (LMMM74, LMMM92, and LMMM100) from vaginal secretion were used in the experiments. In addition, reference strains, including C. albicans ATCC 90028, C. tropicalis ATCC 13803, C. parapsilosis ATCC 22019, C. glabrata ATCC 2001, and C. krusei ATCC 6258, provided by the American Type Culture Collection (ATCC) and the Netherlands Collection Centraalbureau voor Schimmelcultures (CBS), were also employed in the study. The strains were stored at $-80^{\circ} \mathrm{C}$ in Yeast Extract-PeptoneDextrose $(10 \mathrm{~g} / \mathrm{L}$ yeast extract, $20 \mathrm{~g} / \mathrm{L}$ glucose, and $20 \mathrm{~g} / \mathrm{L}$ mycological peptone) containing $20 \%(\mathrm{v} / \mathrm{v})$ glycerol. All the strains belong to the mycological culture collection of the Laboratory of Medical and Molecular Mycology, Department of Clinical and Toxicological Analyses, Federal University of Rio Grande do Norte, Brazil.

\section{Determination of Minimal Inhibitory Concentration (MIC)}

The antifungal susceptibility test was performed using the broth microdilution assay based on protocol M27-A3 of the Clinical and Laboratory Standards Institute (CLSI, 2008), for defining the minimal inhibitory concentrations (MICs) of fluconazole, HECL, BF, and BDP. Fluconazole solution was prepared in line with M27-A3 guidelines; the solution was diluted in RPMI 1640 buffered with 3-(N-morpholino) propanesulfonic acid (MOPS) at $\mathrm{pH}$ 7.0. All the natural products tested were re-suspended in the same culture medium recommended by the CLSI, after solubilization in $0.5 \%$ dimethyl sufoxide (DMSO). To standardize the inoculum, Candida spp. cells were initially cultivated for $24 \mathrm{~h}$ using Sabouraud Dextrose Agar (SDA) at $35^{\circ} \mathrm{C}$, and an initial suspension was adjusted spectrophotometrically to match the $0.5 \mathrm{McF}$ arland scale standard $\left(1-5 \times 10^{6}\right.$ cells $)$ at $530 \mathrm{~nm}$. Subsequently, two serial dilutions were made, the first in saline solution (1:100), and the second in RPMI 1640 (1:20), in order to obtain the final concentration of $10^{3}$ cells $/ \mathrm{mL}$. Afterward, aliquots of $100 \mu \mathrm{L}$ of the final inoculum solution were added to each well with $100 \mu \mathrm{L}$ of different concentrations $(2,500-0.001 \mu \mathrm{g} / \mathrm{mL})$ of HECL, BF, or BDP and $(64-0.03 \mu \mathrm{g} / \mathrm{mL})$ fluconazole. Finally, the microtiter plates were incubated at $37^{\circ} \mathrm{C}$ and the reading was done after $24 \mathrm{~h}$ of incubation for fluconazole, and between 24 and $48 \mathrm{~h}$ for the natural products. In addition, the reference strains C. parapsilosis ATCC22019 (susceptible) and C. krusei ATCC6258 (resistant) were included as control microorganisms for the testing of fluconazole. The MIC was defined as the lowest concentration which showed about 50\% reduction in visual growth as compared to the positive control for fluconazole, HECL, BF, or BDP. The isolates were classified as resistant at the following cutoff point: $\mathrm{MIC} \geq 8 \mu \mathrm{g} / \mathrm{mL}$ to fluconazole for all the Candida spp. tested, except for C. glabrata, where strains with $\mathrm{MIC} \geq 64 \mu \mathrm{g} / \mathrm{mL}$ were considered resistant. Candida krusei is intrinsically resistant to fluconazole (CLSI, 2017). 


\section{Determination of Minimal Fungicidal Concentration (MFC)}

In order to confirm whether the contractions of HECL, BF, and BDP which visually inhibited $100 \%$ of yeast cells' growth in the wells corresponded to the MFC, $10 \mu \mathrm{L}$ aliquots of each well, where no visual growth was detected, and using the same conditions for both the positive and negative controls, were seeded on the surface of SDA and the plates were incubated for $48 \mathrm{~h}$ at $37^{\circ} \mathrm{C}$. The MFC was defined as the lowest concentration of natural products which resulted in no colony forming unit (CFU) growth.

\section{Biofilm Assay}

Biofilm assays were performed based on the method proposed by Chaves et al. (2013). First, $100 \mathrm{~mL}$ aliquots of a standardized cell suspension $\left(10^{7}\right.$ cells $\left./ \mathrm{mL}\right)$ were transferred to microtiter plates and incubated for $1.5 \mathrm{~h}$ at $37^{\circ} \mathrm{C}$ in a shaker at $75 \mathrm{rpm}$. Following the adhesion phase, cell suspensions were aspirated and each well was washed twice with PBS to remove loosely adherent cells. A total of $100 \mu \mathrm{L}$ of Yeast Nitrogen Base medium (YNB) with $50 \mathrm{mM}$ of $\mathrm{g}$ D-glucose monohydrate containing $1,250 \mu \mathrm{g} / \mathrm{mL}$ of HECL and $625 \mu \mathrm{g} / \mathrm{mL}$ of BF and BDP were added to each well and incubated at $37^{\circ} \mathrm{C}$ in a rotatory incubator (Tecnal, TE-420, São Paulo, Brazil) at $75 \mathrm{rpm}$. Biofilms were allowed to develop for $72 \mathrm{~h}$ and were then quantified by crystal violet staining and XTT-reduction assays [2,3-bis(2-methoxy-4-nitro5-sulfophenyl)- $2 H$-tetrazolium-5-carboxanilide]. To perform the crystal violet assay, the biofilm-coated wells from the microtiter plates were washed twice with $200 \mu \mathrm{L}$ of phosphate-buffered saline (PBS) and air dried for $45 \mathrm{~min}$. Subsequently, each well was stained with $110 \mu \mathrm{L}$ of $0.4 \%$ aqueous crystal violet solution for $45 \mathrm{~min}$. Each well was then washed thrice with $300 \mu \mathrm{L}$ of sterile distilled water and immediately distained with $200 \mu \mathrm{L}$ of $95 \%$ ethanol for $45 \mathrm{~min}$. Thereafter, an amount of $100 \mu \mathrm{L}$ of the distaining solution was transferred to a clean well and the absorbance was measured with a microtiter plate reader at $570 \mathrm{~nm}$. For the XTT-reduction assay, the biofilm-coated wells of the microtiter plates were washed twice with $150 \mu \mathrm{L}$ of PBS and an amount of $100 \mu \mathrm{L}$ of XTT/menadione solution (1 $\mu \mathrm{M}$ of menadione) was added to each well containing a prewashed biofilm and the negative control wells. The plates were covered with aluminum foil and incubated in the dark for $2-3 \mathrm{~h}$ at $37^{\circ} \mathrm{C}$. Subsequently, an amount of $75-80 \mathrm{~mL}$ of the solution was removed (the resulting colored supernatant from each well) and transferred to the wells of a new microtiter plate. The solution was measured with a microtiter plate reader at $490 \mathrm{~nm}$.

\section{Analysis of the Synergistic Action of B-Type Dimeric Procyanidin (BDP) From Commiphora leptophloeos With Fluconazole}

The interactions of the C. leptophloeos B-type dimeric procyanidin (BDP) with synthetic antifungal fluconazole (64-0.06 $\mu \mathrm{g} / \mathrm{mL})$ were investigated using the combination method known as "Checkerboard" in 96-well microtiter plates with RPMI 1640 medium. The dilutions of fluconazole were prepared in order to obtain four times the final concentration in the well, with two other dilutions performed on the microplate itself. The dilutions of BDP were prepared in conical tubes for subsequent application in the microplate, in the concentration range of 2,500-1 $\mu \mathrm{g} / \mathrm{mL}$. For the two-dimensional preparation of the microplates (fluconazole vs. BDP), an amount of $50 \mu \mathrm{l}$ of each fluconazole concentration was added to columns 1-10. Subsequently, $50 \mu \mathrm{l}$ of the dilutions of BDP were added to lines A to $\mathrm{G}$. Line $\mathrm{H}$ and column 11 contained only fluconazole and BDP, respectively. Column 12 was assigned to wells without drug (growth control) and wells with only the culture medium (sterility control). The fractional inhibitory concentration index (FICI) was used for interpreting the results. The FICI was calculated based on the following equation: FICI = FIC A + FIC $\mathrm{B}$; where, FIC A is the ratio of the combination MIC to the MIC of substance A alone, and FIC B is the ratio of the MIC of the combination to the MIC of substance B alone. The interaction was defined as synergistic, indifferent, and antagonistic if the FICIs were $0.5,0.5-4.0$, and 4, respectively (Aslani et al., 2018).

\section{Statistical Analysis}

The data obtained were expressed as mean \pm SD. Differences in statistical analyses were evaluated by One-way analysis of variance (ANOVA) with Tukey's test and the Spearman coefficient was used to assess the correlation between the different techniques employed for quantifying the biofilm formed. Both methods were executed using GraphPad Prism version 5.0 (GraphPad software, San Diego, CA, United States), with statistical significance of ${ }^{* * *} p<0.001,{ }^{* *} p<0.01$, and ${ }^{*} p<0.05$.

\section{RESULTS}

\section{Phytochemical Study of Commiphora leptophloeos}

The phytochemical profile of HECL and BF was initially characterized by mass spectrometry which indicated the presence of quinic acid and oligomeric procyanidins derived exclusively from flavan-3-ol. The second order fragmentation (MS/MS) of the precursor ion at $\mathrm{m} / z 191$ led to the identification of quinic acid (QA). The main precursor ions at $m / z 289,577,865,1,153$, 1,441 , and 1,729 allowed the identification of the oligomeric series composed of one to six units of flavan-3-ols (monomer, dimer, trimer, tetramer, pentamer, and hexamer, respectively), thus confirming the presence of B-type oligomeric procyanidins (Figures 1A,B and Table 1).

It is worth noting that, although HECL and BF exhibited the same phytochemical profile, the CTP of BF $(383.67 \pm 0.02 \mathrm{mg}$ of GAE/g) was higher compared to that of HECL $(350.82 \pm 0.05 \mathrm{mg}$ of $\mathrm{GAE} / \mathrm{g}$ ). The liquid-liquid extraction helped concentrate the polyphenols in $\mathrm{BF}$, which, through fractioning by $\mathrm{CPC}$, resulted in 25 sub-fractions (SF). These sub-fractions were analyzed by TLC and subsequently by ${ }^{1} \mathrm{H}$ NMR and mass spectrometry. The results obtained from the analysis showed that SF-6 was a pure compound (purity $>95 \%$ HPLC) identified as B-type dimeric procyanidin (BDP) (Figure 2). The BDP was isolated as a brownish white powder; the result obtained from the analysis of the BDP by TLC showed a single red band after revelation with vanillin sulfuric. The quantity of BDP yielded was $89 \mathrm{mg}$ (1.48\%); this was obtained after $8 \mathrm{~h}$ of CPC analysis. 

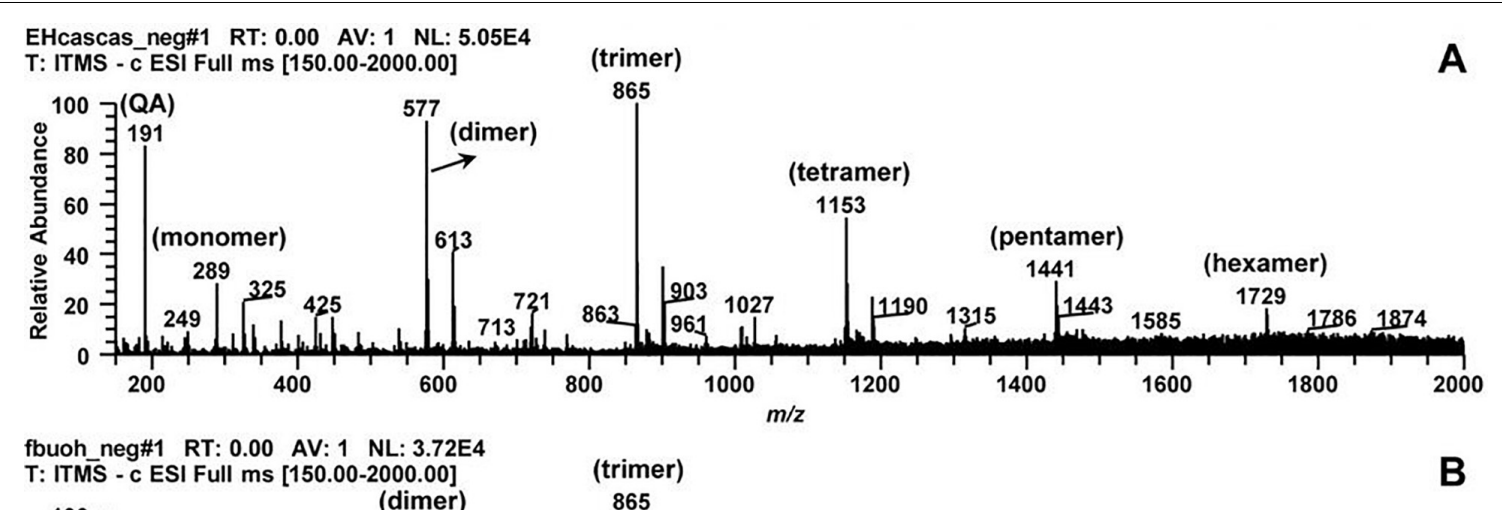

B

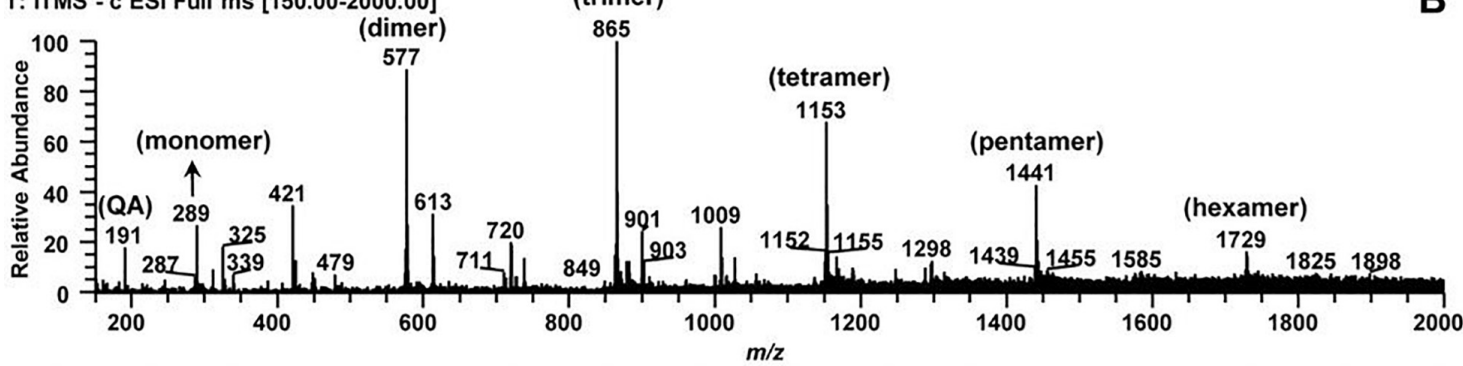

FIGURE 1 | Typical direct flow injection ESI-IT-MS fingerprint spectra obtained in negative ion mode for Commiphora leptophloeos hydroethanolic extract in mass scan in the range of $\mathrm{m} / \mathrm{z}$ 210-2000. (A) Commiphora leptophloeos hydroethanolic extract (HECL). (B) $n$-butanol fraction (BF). QA, quinic acid. Monomer, dimer, trimer, tetramer, pentamer, and hexamer of procyanidins.

BDP analysis by MS spectrometry showed a molecular ion at $\mathrm{m} / \mathrm{z} 577[\mathrm{M}-\mathrm{H}]^{-}$, which was found to be compatible with the molecular formula $\mathrm{C}_{30} \mathrm{H}_{25} \mathrm{O}_{12}$ (Figure $\mathbf{1}$ and Table 1). This result is in line with the reports in the literature (Czerwińska et al., 2018). Finally, the chemical structure of BDP was elucidated and confirmed through a comparative analysis of the ${ }^{1} \mathrm{H}$ NMR spectra and the data from studies published in the literature (Shoji et al., 2003). The ${ }^{1} \mathrm{H}$ NMR spectra of the BDP exhibited methylene proton signals at $\delta \mathrm{H} 2.53$ and 2.58 , which were assigned to the 4-position of the $\mathrm{A}$ unit as a (+)-catechin moiety. Next, the proton signals at the 2 - and 3-positions of the A unit were assigned to $\delta \mathrm{H} 4.96$ and 4.16. The interflavanoid bond between units $\mathrm{A}$ and $\mathrm{B}$ was assigned to the proton signal $(\delta \mathrm{H} \mathrm{4.61)}$ at position 4 of unit $\mathrm{B}$ and

TABLE 1 | Compounds identified in Commiphora leptophloeos hydroethanolic extract (HECL) and n-butanol fraction (BF) by FIA-ESI-IT-MS/MS.

\begin{tabular}{lccc}
\hline Compound identified & $\begin{array}{c}\mathbf{~ M - H ]}^{-} \\
\mathbf{m / z}\end{array}$ & MS/MS $\mathbf{~ m / z}$ & References \\
\hline Quinic acid & 191 & 173,85 & Zhang et al., 2018 \\
Flavan-3-ol (catechin) & 289 & 271,137 & Jiang et al., 2020 \\
B-type dimeric procyanidin & 577 & $451,425,289$ & Jiang et al., 2020 \\
B-type trimeric procyanidin & 865 & 577,289 & Jiang et al., 2020 \\
B-type tetrameric procyanidin & 1,153 & $865,577,289$ & Jiang et al., 2020 \\
B-type pentameric procyanidin & 1,441 & $1,153,865$, & Jiang et al., 2020 \\
& & 577,289 & \\
B-type hexameric procyanidin & 1,729 & $1,441,1,153$, & Jiang et al., 2020 \\
& & $865,577,289$ &
\end{tabular}

the proton signal $(\delta \mathrm{H} 4.95)$ at position 2 of unit A (Figure 2 and Supplementary Figure S1). The combination of the results obtained from the UV, MS, and 1H NMR analyses helped determine that the compound isolated from BF was B-type dimeric procyanidin.

The HPLC-PD/ELSD method (Figure 3) used for rapid simultaneous quantification of the total content of procyanidins in HECL proved to be specific and selective. A comparison of all the peaks of the chromatographic profile of the extract (HECL) and the BDP revealed a single maximum UV absorption band at $280 \mathrm{~nm}$ (Supplementary Figure S2), which was found to be typical for flavan-3-ol derivatives (Vidal-Gutiérrez et al., 2020), and spectral similarity indices greater than 0.99 (Tables 2, 3).

As shown in Figure 3, the application of the HPLCPDA/ELSD technique resulted in a separation with a high resolution of the compounds of interest. Peaks 1-5 identified in HECL were quantified using the BDP calibration curves by the external standard method. The BDP calibration curve was linear with a correlation coefficient $r=0.9902$, while the values obtained for LOD $(21.90 \mu \mathrm{g} / \mathrm{mL})$, LOQ $(66.38 \mu \mathrm{g} / \mathrm{mL})$, and precision (\% RSD $\leq 4.50$ ) were found to be satisfactory (Table 2).

\section{In vitro Hemolytic Activity}

The cytotoxicity of the HECL, BF, and BDP of C. leptophloeos in human erythrocytes was evaluated by testing the hemolytic activity in various concentrations $(19.5-625 \mu \mathrm{g} / \mathrm{mL})$. The HECL, $\mathrm{BF}$, or BDP were not found to be cytotoxic, since they did not present a significant effect on the lysis of human erythrocytes under all the concentrations tested in the study (Figure 4). The 
<smiles>Oc1cc(O)c2c(c1)O[C@H](c1ccc(O)c(O)c1)C(O)[C@H]2c1c(O)cc(O)c2c1O[C@H](c1ccc(O)c(O)c1)C(O)C2</smiles>

FIGURE 2 | Chemical structure of B-type dimeric procyanidin (BDP).

hemolytic activity assays served as a basis for determining the concentrations used for assessing antifungal activity.

\section{Antifungal and Antibiofilm Activities}

Possible antifungal activity of the HECL, BF and BDP of C. leptophloeos was evaluated against a panel of 14 clinical and reference strains (including fluconazole-resistant strains) of the Candida spp. through the determination of MIC and MFC using the broth microdilution test. All the three natural compounds
(HECL, BF, and BDP) evaluated here exhibited antifungal activity against all the clinical and reference strains of the Candida spp. tested. However, the inhibition concentrations varied among the isolates. The MICs ranged from 156.2 to $2,500 \mu \mathrm{g} / \mathrm{mL}$ for HECL and BDP, while the MICs for BF varied between 312.5 and $2,500 \mu \mathrm{g} / \mathrm{mL}$. In addition, BDP showed fungicidal activity; this was determined by the absence of CFU growth observation on the SDA plates after incubation, with concentrations ranging from 1250 to $2,500 \mu \mathrm{g} / \mathrm{mL}$ (Table 4 ).

The antibiofilm activity of HECL, BF, and BDP was evaluated against five clinical isolates of Candida spp. obtained from blood cultures and vulvovaginal secretion using two different quantification methodologies: crystal violet staining and XTTreduction. All the clinical isolates selected were previously considered biofilm producers. C. tropicalis (LMMM447 and LMMM195) and C. albicans LMMM92 were considered strong biofilm-producing strains. C. albicans LMMM100 was classified as a moderate producer of biofilm, and C. krusei LMMM249 was considered a weak biofilm-producing strain, based on the study conducted by Stepanović et al. (2007). It is worth noting that the concentration of $625 \mu \mathrm{g} / \mathrm{mL}$ was used for testing antibiofilm activity in the presence of BF and BDP, whereas a double of this concentration was chosen $(1,250 \mu \mathrm{g} / \mathrm{mL})$ for testing antibiofilm activity in HECL; this is because, in general, higher MICs were necessary to inhibit Candida growth in the presence of the hydroethanolic extract. Biofilm formation was found to be significantly impaired $(p<0.001)$ in C. tropicalis LMMM447, C. tropicalis LMMM195, C. albicans LMMM92, and C. albicans LMMM100. The percentage of inhibition ranged from 65 to $100 \%$ when the cells were treated with HECL, BF, or BDP for both

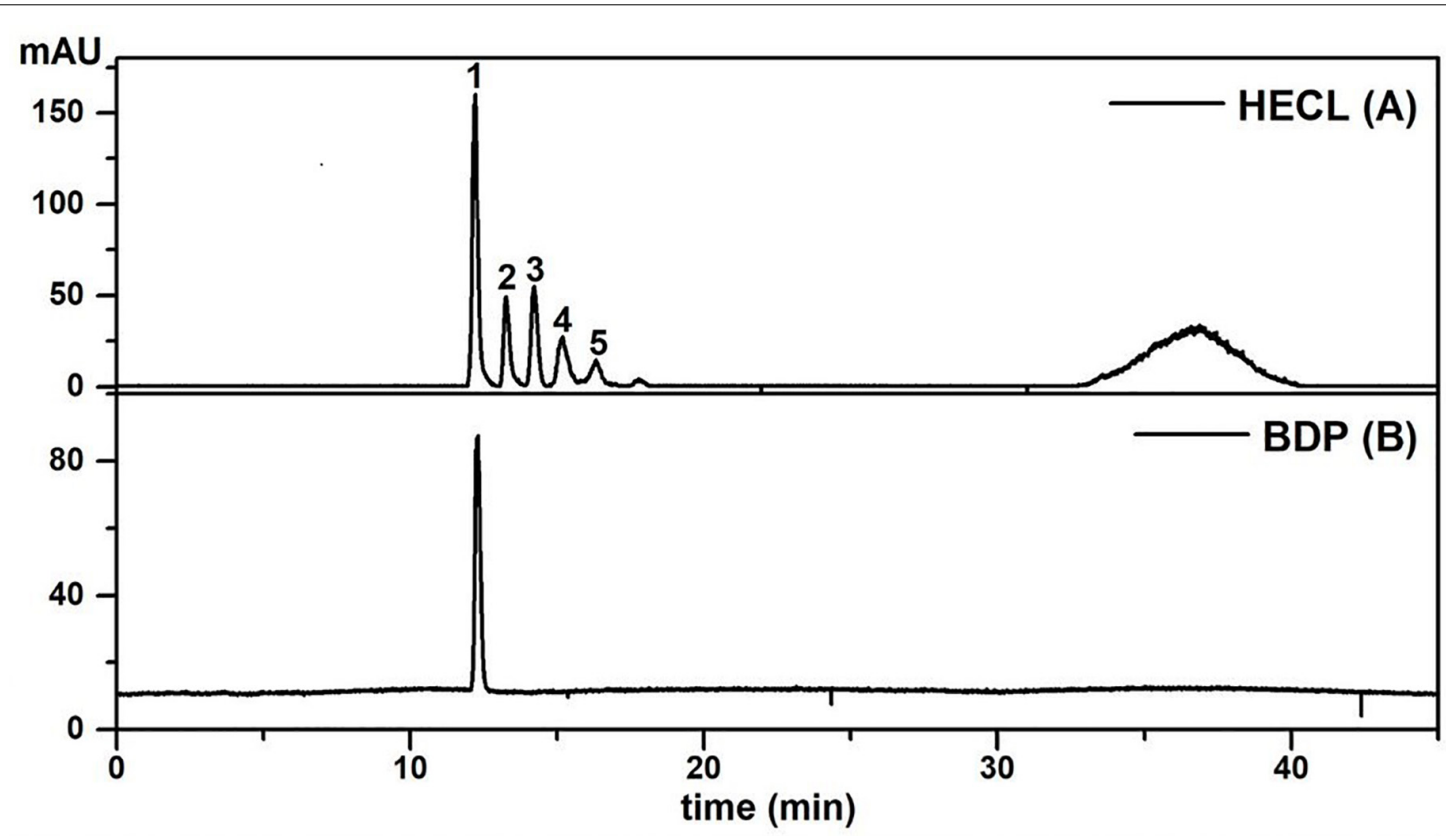

FIGURE 3 | HPLC-ELSD profiles of Commiphora leptophloeos hydroethanolic extract and isolated compound employed under the conditions described in the chromatographic section. (A) Commiphora leptophloeos hydroethanolic extract (HECL). (B) B-type dimeric procyanidin (BDP). Numbered chromatographic peaks refer to quantified compounds. 
TABLE 2 | Validation parameters of the analytical method for quantifying the content of B-type oligomeric procyanidin in Commiphora leptophloeos hydroethanolic extract by HPLC-PAD/ELSD.

\begin{tabular}{|c|c|c|c|c|c|c|}
\hline Compound & Rt (min) & $\begin{array}{c}\text { Curve } \\
\text { calibration }\end{array}$ & $r$ & $\begin{array}{c}\text { LOD } \\
(\mu \mathrm{g} / \mathrm{mL})\end{array}$ & $\begin{array}{c}\text { LOQ } \\
(\mu \mathrm{g} / \mathrm{mL})\end{array}$ & $\begin{array}{c}\text { Precision } \\
\text { (\%RSD) }\end{array}$ \\
\hline 1 & 12.39 & $\begin{array}{c}y= \\
4795.3 \times- \\
106\end{array}$ & 0.9902 & 21.90 & 66.38 & 4.50 \\
\hline
\end{tabular}

1: BDP; r: coefficient of correlation; Rt, retention time; $L O D$, detection limit; $L O Q$, quantitation limit; $r, R S D$, relative standard deviation; $n=5$.

TABLE 3 | Peak number, retention time, indices of spectral similarity and content of oligomeric procyanidins in Commiphora leptophloeos hydroethanolic extract (HECL) by HPLC-PDA/ELSD.

\begin{tabular}{lcccc}
\hline Peak & Rt (min) & $\begin{array}{c}\text { Similarity } \\
\text { index }\end{array}$ & $\begin{array}{c}\text { Compound } \\
\text { content (mg/g } \\
\text { of HECL) }\end{array}$ & Compound name \\
\hline 1 & 12.39 & 1.0000 & 64.16 & B-type dimeric procyanidin \\
2 & 13.07 & 0.9992 & 35.10 & B-type trimeric procyanidin \\
3 & 13.96 & 0.9986 & 38.50 & B-type tetrameric procyanidin \\
4 & 14.65 & 0.9978 & 33.33 & B-type pentameric procyanidin \\
5 & 15.90 & 0.9973 & 27.44 & B-type hexameric procyanidin
\end{tabular}

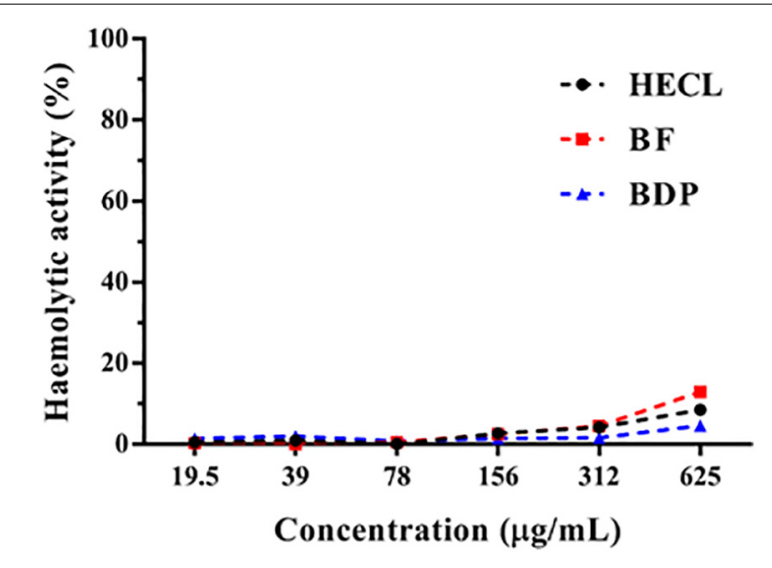

FIGURE 4 | Percentage of hemolytic activity of Commiphora leptophloeos hydroethanolic extract (HECL), $n$-butanol fraction (BF), and B-type dimeric procyanidin (BDP).

crystal violet staining and XTT-reduction assays. Interestingly, with regard to C. krusei LMMM249 strain, only BDP significantly reduced $(p<0.001)$ biofilm formation when crystal violet staining was used for quantification; furthermore, BF showed a statistically significant reduction of biofilm formation when XTT was used for quantifying the metabolic activity of sessile cells. $\mathrm{BF}$ and BDP showed a relatively greater antibiofilm potential compared to HECL. Similarly, BDP was able to significantly inhibit $(p<0.001)$ biofilm formation for most of the clinical strains tested, with a percentage of inhibition up to $100 \%$ (Figure 5). It is worth pointing out that a positive correlation was found between the two methodologies used for quantifying the formation of biofilm $(r=0.8783)$.

\section{Analysis of the Synergistic Action of B-Type Dimeric Procyanidin (BDP) From Commiphora leptophloeos With Fluconazole}

Considering the results obtained from the antifungal activity assay, the combined action of BDP with fluconazole was investigated for the biofilm producing strains. Table 5 shows the results obtained from this analysis. As can be observed, among the strains analyzed, the combination of the two substances was shown to be synergistic for the following strains: C. albicans (LMMM 92), C. albicans (LMMM100), and C. tropicalis (LMMM195). In contrast, with regard to C. krusei (LMMM249) and C. tropicalis (LMMM447), there was an indifferent effect (without interaction) relative to the combined action of the substances under test; surprisingly though, the values obtained were close to 0.5 , and this pointed to a trend of synergistic action even for these strains. The synergistic effect between fluconazole and BDP helped reduce the MIC of this natural product by $4 \times$ for C. albicans (LMMM100), $8 \times$ for C. albicans (LMMM92), and $16 \times$ for C. tropicalis (LMMM447). No antagonism was observed in the combination test for any of the strains investigated.

\section{DISCUSSION}

\section{Phytochemical Study of Commiphora leptophloeos}

Few studies have reported the presence of condensed tannins in species of the Commiphora genus. Terpenoids are specialized metabolites which have been widely associated with the genus (Shen et al., 2012; Da Silva et al., 2015). Phytochemical screening studies published in the literature have indicated the presence of tannins in different C. leptophloeos stem bark extracts (Trentin et al., 2011; Chaves et al., 2016; Lima et al., 2017). However, the results have not been well understood particularly with respect to the class of tannins, and only few studies have managed to perform a complete phytochemical characterization of these compounds (Trentin et al., 2013; Pereira et al., 2017; Da Silva et al., 2019). To date, quantitative phytochemical data on the species remain scarce. Bearing that in mind, the present study sought to conduct a complete qualitative and quantitative phytochemical characterization of the hydroethanolic extract of C. leptophloeos stem bark and investigate the cytotoxic properties, as well as antifungal and antibiofilm activities, of the extract against the strains of Candida spp.

The results obtained from our qualitative phytochemical characterization of HECL and BF by MS indicated the presence of quinic acid and six B-type oligomeric procyanidins composed of up to six units of flavan-3-ols. The fragmentation of the precursor ion at $m / z 191$ generated the ions at $m / z 173[\mathrm{M}-18-\mathrm{H}]^{-}$and $m / z 75[\mathrm{M}-116-\mathrm{H}]^{-}$. This fragmentation pattern, which is in agreement with reports published in the literature, implies the presence of quinic acid (Zhang et al., 2018). The precursor ion at $m / z 289$ was attributed to the deprotonated molecule of flavan3-ol (catechin), whose fragmentation generated the ions at $\mathrm{m} / \mathrm{z}$ $271[\mathrm{M}-18-\mathrm{H}]^{-}$and $\mathrm{m} / z 137$ [M-152-H] $^{-}$(Jiang et al., 2020). 
TABLE 4 | Minimal inhibitory concentration (MIC) and minimal fungicidal concentration (MFC) of fluconazole (FCZ), Commiphora leptophloeos hydroethanolic extract (HECL), $n$-butanol fraction (BF), and B-type dimeric procyanidin (BDP) against Candida spp. determined based on the microdilution technique with visual readings of cell turbidity after $24 \mathrm{~h} / 48 \mathrm{~h}$ incubation at $37^{\circ} \mathrm{C}$ in RPMl 1640.

\begin{tabular}{|c|c|c|c|c|c|}
\hline \multirow[t]{2}{*}{ Strains } & \multirow{2}{*}{$\frac{\mathrm{FCZ}(\mu \mathrm{g} / \mathrm{mL})}{\mathrm{MIC}^{*}}$} & \multirow{2}{*}{$\frac{\text { HECL }(\mu \mathrm{g} / \mathrm{mL})}{\text { MIC }}$} & \multirow{2}{*}{$\frac{\mathrm{BF}(\mu \mathrm{g} / \mathrm{mL})}{\mathrm{MIC}}$} & \multicolumn{2}{|c|}{$\mathrm{BDP}(\mu \mathrm{g} / \mathrm{mL})$} \\
\hline & & & & MIC & $\mathrm{MFC}^{\star \star}$ \\
\hline Candida albicans (ATCC90028)S & 0.125 & 2,500 & 2,500 & 625 & 1,250 \\
\hline Candida albicans (LMMM74) ${ }^{S}$ & 0.5 & 1,250 & 2,500 & 625 & 1,250 \\
\hline Candida albicans (LMMM92)s & 0.5 & 2,500 & 2,500 & 312.5 & 2,500 \\
\hline Candida albicans (LMMM100)S & 2.0 & 1,250 & 2,500 & 1,250 & 2,500 \\
\hline Candida glabrata (ATCC 2001) ${ }^{S}$ & 0.5 & 2,500 & 2,500 & 1,250 & 2,500 \\
\hline Candida glabrata (LMMM704) $)^{S}$ & 0.125 & 2,500 & 1,250 & 625 & 2,500 \\
\hline Candida krusei (ATCC 6258) ${ }^{R}$ & $\geq 16$ & 625 & 312.5 & 156.2 & 1,250 \\
\hline Candida krusei (LMMM249) ${ }^{R}$ & $\geq 16$ & 2,500 & 2,500 & 1,250 & 2,500 \\
\hline Candida parapsilosis (ATCC 22019)S & 0.5 & 2,500 & 2,500 & 312.5 & 2,500 \\
\hline Candida parapsilosis (LMMM85) ${ }^{S}$ & 2.0 & 2,500 & 1,250 & 625 & 2,500 \\
\hline Candida parapsilosis $(\mathrm{LMMM} 83)^{R}$ & $\geq 16$ & 156.2 & 625 & 312.5 & 2,500 \\
\hline Candida tropicalis (ATCC 13803) ${ }^{R}$ & $\geq 16$ & 2,500 & 2,500 & 1,250 & 2,500 \\
\hline Candida tropicalis $\left(\mathrm{LMMM195)^{S }}\right.$ & 2.0 & 2,500 & 312.5 & 1,250 & 2,500 \\
\hline Candida tropicalis (LMMM447) $)^{\mathrm{S}}$ & 2.0 & 2,500 & 312.5 & 312.5 & 2,500 \\
\hline
\end{tabular}

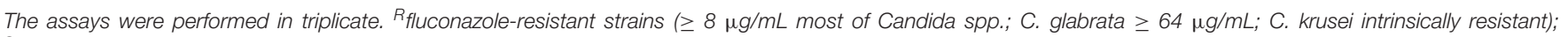

S fluconazole-susceptible or SDD strains $(\leq 16 \mu \mathrm{g} / \mathrm{mL}) ; \mathrm{MIC}^{*}$, minimal inhibitory concentration; MFC**, minimal fungicidal concentration.

The precursor ion at $m / z 577$ indicated the presence of the deprotonated B-type dimeric procyanidin molecule. The fragmentation of this ion produced the ion at $\mathrm{m} / z \quad 451$ $[\mathrm{M}-126-\mathrm{H}]^{-}$, formed by the fragmentation of the heterocyclic ring fission with the elimination of the upper ring $\mathrm{A}$, which indicated the presence of two hydroxyl groups in this ring. The product ion at $m / z 425[\mathrm{M}-152-\mathrm{H}]^{-}$was generated by cleavage via Retro Diels-Alder with the elimination of ring $\mathrm{B}$, and indicated the presence of two hydroxyl groups in this


formed by cleavage via methyl quinone (Czerwińska et al., 2018; Jiang et al., 2020). Thus, two units (upper and lower) of this dimer were identified as flavan-3-ols; as such, the main ions at $\mathrm{m} / z 865,1,153,1,441$, and 1,729 were found to correspond to the deprotonated molecules of the trimer, tetramer, pentamer, and hexamer of flavan-3-ols, respectively. This outcome was attributed to the consecutive -288 Da losses that occurred through the methyl quinone cleavage pathway, suggesting the presence of B-type oligomeric procyanidins composed of one to six flavan-3-ols units (Jiang et al., 2020; Table 1).

Previous phytochemical studies have reported the presence of phenolic acids, such as gallic acid, chlorogenic acid, protocatequic acid, and A- and B-type polymeric proanthocyanidins, in C. leptophloeos extract (Trentin et al., 2013; Pereira et al., 2017; Da Silva et al., 2019). Compared to the previously reported studies in the literature, the distinguishing feature of the phytochemicals found in our technique may possibly be related to the nature of the extractive solution. The extraction of polyphenols depends on the polarity of the solvent due to the greater affinity of these compounds for polar solvents (Tanaka et al., 2018). Thus, the hydroethanolic solvent seemed to have a more adequate polarity to extract greater amounts of phenolic compounds (without interference from other compounds) than the other solvents used previously, such as cyclohexane, chloroform, ethyl acetate, methanol, and water (Pereira et al., 2017). Furthermore, the high solar radiation which characterizes the climate conditions of the Brazilian caatinga biome clearly contributes to great biosynthesis diversity and increases in the content of phenolic compounds present in the plant species (Biasi-Garbin et al., 2016).

Another interesting point worth mentioning is that the present study obtained oligomeric procyanidins-rich fraction with a high polyphenol content which was subjected to fractionation by CPC. The separation method conducted by CPC was found to be efficient, especially for polar substances that are often difficult to separate by classic chromatographic methods (Rohr et al., 2000). The CPC fractionation process, in a single step, enabled us to isolate $89 \mathrm{mg}$ of BDP with high purity, in a few hours of analysis.

BDP belongs to an important class of condensed tannins which has been investigated recently due to its potential health-promoting effects, including antiviral, antibacterial, antileishmanial, anti-inflammatory, and antioxidant effects (Tanaka et al., 2018; Tocci et al., 2018).

Among the novelties of the present work is the fact that it is the first study that has employed the CPC technique for the analysis of C. leptophloeos. Trentin et al. (2013) have previously conducted a study which involved the analysis of a polymeric proanthocyanidins-rich fraction from C. leptophloeos aqueous extract using classical column chromatography, where the authors were able to identify the constituents of the fraction by MALDI-TOF-MS, but did not obtain pure compounds. Another interesting work that 

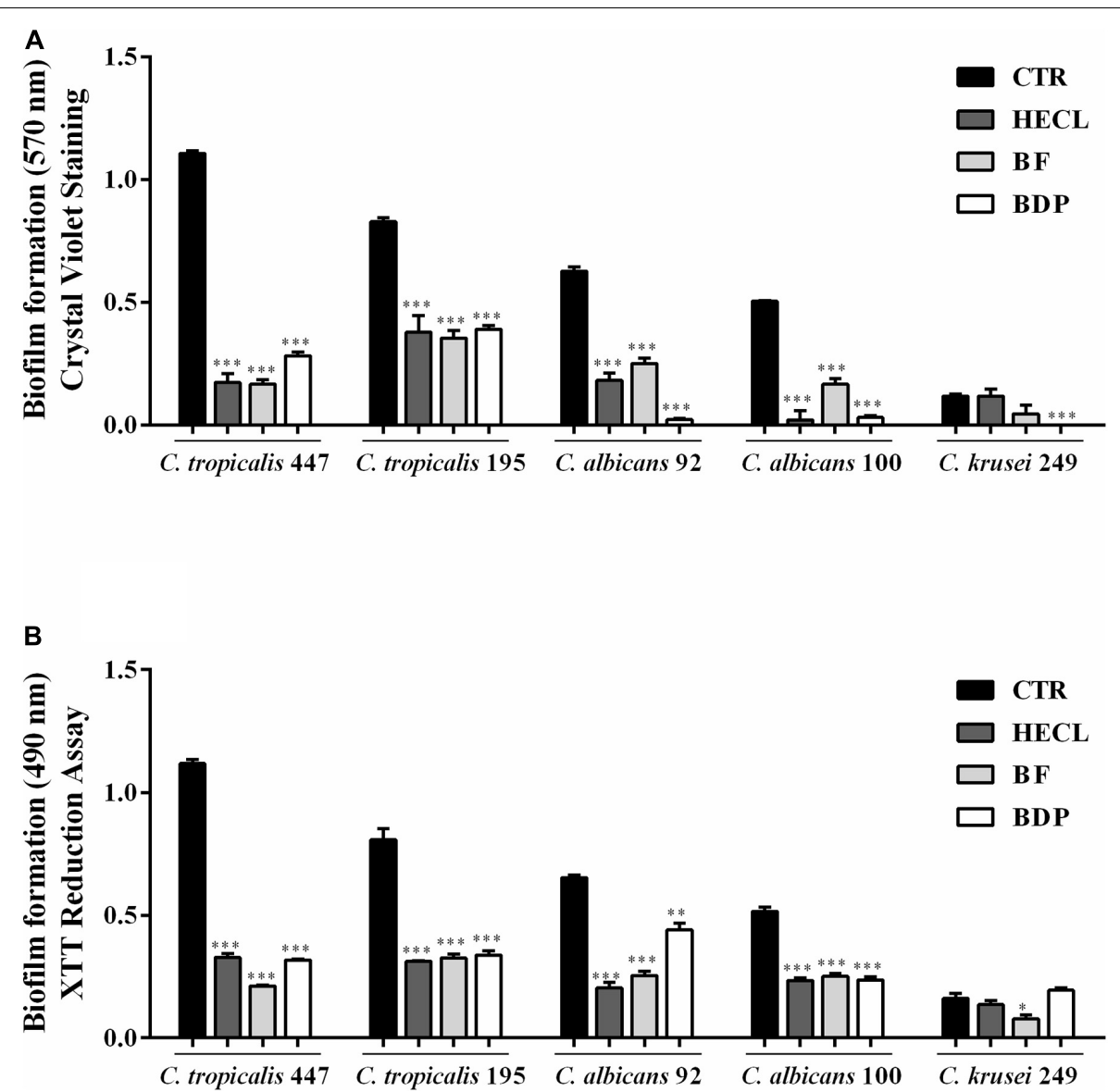

FIGURE 5 | Effect of Commiphora leptophloeos hydroethanolic extract (HECL), $n$-butanol fraction (BF), and B-type dimeric procyanidin (BDP) on biofilm of Candida tropicalis LMMM447, C. tropicalis LMMM195, C. albicans LMMM92, C. albicans LMMM100, and C. krusei LMMM249 clinical isolates. (A) Crystal violet and (B) XTT assay. Values are expressed as mean $\pm \mathrm{SD}, n=5$. ${ }^{* * *} p<0.001$ compared with control (CTR, medium + yeast). HECL, Commiphora leptophloeos hydroethanolic extract (1,250 $\mu \mathrm{g} / \mathrm{mL})$; BF, $n$-butanol fraction $(625 \mu \mathrm{g} / \mathrm{mL})$, and BDP, B-type dimeric procyanidin $(625 \mu \mathrm{g} / \mathrm{mL})$.

deserves mentioning was the study conducted by Pereira et al. (2017) which isolated a lignan, identified as hinokinin, from cyclohexanic extracts through a tedious fractionation

TABLE 5 | Synergistic effects of B-type dimeric procyanidin (BDP) from Commiphora leptophloeos and fluconazole (FCZ) on Candida spp.

\begin{tabular}{lcccc}
\hline Strains & \multicolumn{4}{c}{ MIC } \\
\cline { 2 - 5 } & $\begin{array}{c}\text { BDP } \\
(\mu \mathbf{g} / \mathbf{m L})\end{array}$ & $\begin{array}{c}\text { FCZ } \\
(\mu \mathbf{g} / \mathbf{m L})\end{array}$ & FICl & Effect \\
\hline Candida albicans (LMMM 92) & 2,500 & 2.0 & 0.37 & Synergistic (8×) \\
Candida albicans (LMMM100) & 2,500 & 2.0 & 0.50 & Synergistic (4×) \\
Candida krusei (LMMM249) & 1,250 & 16.0 & 0.56 & No interaction \\
Candida tropicalis (LMMM195) & 1,250 & 2.0 & 0.31 & $\begin{array}{c}\text { Synergistic } \\
(16 \times)\end{array}$ \\
Candida tropicalis (LMMM447) & 1,250 & 1.0 & 0.52 & No interaction
\end{tabular}

The minimal inhibitory concentration (MICS) values of BDP and fluconazole were obtained in the test, along with the fractional inhibitory concentration index (FICI) and the effect resulting from the interaction of the substances. Values obtained using the checkerboard technique after incubation at $37^{\circ} \mathrm{C}$ for $48 \mathrm{~h}$. process by flash chromatography using a silica gel column. Considering the scarcity of studies in the literature, the technique adopted in the present study unfolds new possibilities for the application of CPC toward a single-step isolation of bioactive oligomeric procyanidins from C. leptophloeos; the technique could also be applied for the characterization of other plant extracts.

To aid the quality control analysis of C. leptophloeos, the present study successfully developed an analytical method by HPLC-PDA/ELSD which allowed the simultaneous quantification of five B-type oligomeric procyanidins with good linearity, specificity, precision, and selectivity response and with satisfactory values of LOD and LOQ. Based on the results obtained, BDP was identified as the major substance in HECL, since it is in greater quantity than other substances. In this sense, BDP can be suitably employed as a specific analytical marker for the extract of C. leptophloeos. This newly developed HPLC-PDA/ELSD method could potentially be applied for the quantification and authentication of other matrices of natural origin. 


\section{In vitro Hemolytic Activity}

Considering the adverse effects associated with the prolonged use of antifungal drugs and the fact that these effects can often overlap with the therapeutic effects, the search for bioactive substances with minimal toxicity is of great importance in the development of new antifungal agents (Fuentefria et al., 2018). In this context, it is necessary to assess the toxicity of new natural products with potential antifungal activity in order to have a better understanding of any potentially harmful adverse effects associated with the prolonged use of these products (Campoy and Adrio, 2017).

Based on the results obtained from the hemolytic activity analysis, the HECL, BF, and BDP were found to be safe in biologically active concentrations, since they did not cause significant cytotoxic effects in human erythrocytes. The noncytotoxic effects observed in this study corroborate with the results obtained by Pereira et al. (2017), in which various C. leptophloeos extracts (cyclohexanic, chloroformic, ethyl acetate, methanolic, and aqueous) were found to be safe in the hemolytic activity test. Hexanic and methanolic extracts of C. leptophloeos have also been found to exhibit low cytotoxicity against HEp-2 and NCI-H292 tumor cells (Melo et al., 2017). Taking the findings of these studies into account, one can conclude that the low cytotoxicity observed for C. leptophloeos may be related, at least in part, to the presence of tannins (Melo et al., 2017; Macedo et al., 2018). In fact, the toxicity of tannins are considerably lower compared to other secondary metabolites with antifungal potential such as alkaloids and terpenoids (Tanaka et al., 2018).

\section{Antifungal and Antibiofilm Activities}

Few studies published in the literature have shed light on the antifungal activity of C. leptophloeos, and most of these studies have confined their attention solely to the antibacterial activity of C. leptophloeos (Trentin et al., 2013; Pereira et al., 2017; Da Silva et al., 2019). Pereira et al. (2017) recently described the antifungal activity of various C. leptophloeos extracts (cyclohexanic, chloroformic, ethyl acetate, methanolic, and aqueous) against reference strains of $C$. albicans and Aspergillus sp. Based on the findings of their study, the extracts exerted antifungal activity only when the concentrations were very high, with MIC values ranging from 6.25 to $12.5 \mathrm{mg} / \mathrm{mL}$ for C. albicans, and from 3.12 to $12.5 \mathrm{mg} / \mathrm{mL}$ for Aspergillus sp. The concentrations reported by Pereira et al. (2017) were up to 10 times higher than the concentrations employed in our present study for HECL, where MIC values ranged from 312.5 to $2,500 \mu \mathrm{g} / \mathrm{mL}$ for C. albicans (Table 4). Similarly, the polyphenols content of HECL in our study was approximately 10 times higher than that of the extracts reported by Pereira et al. (2017). This can be attributed to the fact that the polarity of the extracting solvents directly influences the chemical constitution and the content of secondary metabolites in the extracts, and this consequently affects the antifungal activity (Rohr et al., 2000). Thus, our conclusion is that polyphenols, especially oligomeric procyanidins, are responsible for the stronger antifungal activity observed in the present study.
Our results corroborate with those of Ming et al. (2002) who showed that B-type dimeric and trimeric procyanidins presented antifungal activity against C. albicans (MIC $=150 \mu \mathrm{g} / \mathrm{mL}$ ). Since these procyanidins have been identified in satisfactory amounts in HECL, we share the view that BDP can act alone or in synergy with other oligomeric procyanidins, such as B-type trimeric procyanidin, to inhibit the growth of $C$. albicans strains or cause their cell death. Furthermore, BDP has been reported to exhibit antibacterial activity against Staphylococcus aureus (Ming et al., 2002).

Biofilm is one of the most prevalent forms of growth in nature, defined as a microbial community embedded in an extracellular matrix and adhered to surfaces. Hence, microorganisms in biofilm are more resistant to antimicrobial agents than planktonic cells (Sherry et al., 2017). HECL, BF, and DBP exhibited more than a $65 \%$ inhibition rate of biofilm formation for most of the clinical isolates of Candida spp. investigated in this study. However, less effective antibiofilm activity was observed for HECL and BF against C. krusei. This result may be partially attributed to the fact that the strain tested is a low biofilm producer; apart from that, procyanidins are natural reddish pigments of the anthocyanidin class (Rohr et al., 2000). Although several washing steps are performed before biofilm staining, the pigments might have influenced the optical density (O.D) readings, particularly in this naturally low biofilm producer strain. In addition, despite the intrinsic resistance of C. krusei to fluconazole, new functionalized analogs from the fluconazole triazole ring have demonstrated efficacy against fluconazole-resistant isolates of C. krusei (Motahari et al., 2018; Mahmoudi et al., 2019).

The most remarkable finding of our study has to do with the effect of BDP in relation to HECL and BF. Based on the results obtained, BDP significantly inhibited biofilm formation in most of the clinical isolates tested; in fact, it exhibited inhibition percentage of up to $100 \%$. Clearly, this points to the importance of obtaining new compounds for the identification of potential antifungal targets.

This result was confirmed through the application of two different methodologies for quantifying biofilm production (crystal violet staining and XTT-reduction assay). It is worth mentioning that these techniques are complementary to one another in the sense that while crystal violet stains biofilm biomass (including the exopolymeric matrix), XTT reduction is related to biofilm metabolic activity. Thus, it is likely that BDP causes cell death and contributes toward the reduction of a wellstructured biofilm (Melo et al., 2011). Furthermore, it has been reported that aqueous and ethanolic extracts of C. leptophloeos prevented biofilm formation caused by Staphylococcus spp. and Pseudomonas aeruginosa through bacteriostatic properties (Trentin et al., 2011, 2013; Da Silva et al., 2019).

Although it is evident that oligomeric procyanidins are capable of impairing the full expression of the virulence factors of Candida spp., such as biofilm formation, the possible mechanism of action has not yet been fully elucidated. The literature shows that procyanidins are able to reduce the secretion of proteinases, due to their ability to complex with proteins, and can inhibit phospholipase activity (Macáková et al., 2014; 
Rauf et al., 2019). Tannins have also been shown to rupture the cell wall and plasma membrane, as well as inhibit $1,3-\beta$-D-glucan synthase (PbFKS1) transcript accumulation, which is involved in cell wall synthesis (Zambuzzi-Carvalho et al., 2013; Trolezi et al., 2017). Thus, the antifungal activity of C. leptophloeos observed in this study may be related to the reduction of the production of hydrolytic enzymes, biofilm formation, and/or damage of cell wall and plasma membrane (primary cell targets) of Candida cells.

The simultaneous use of antimicrobial agents can maximize the chances of success in the therapeutic process, thus improving the spectrum of action, optimizing the time of intervals and treatment doses, and even reducing the concentration of the antifungal product employed (Herrera et al., 2010; De Oliveira et al., 2014; Salazar-Aranda et al., 2015; Li et al., 2017). The synergistic action of BDP with fluconazole observed for most of the strains tested may be considered an interesting alternative for the treatment of fungal infections. The enhanced effect of fluconazole (which targets $14 \alpha$-demethylase-an intermediate molecule of ergosterol biosynthesis) combined with BDP may possibly be related to the affinity of procyanidins for ergosterol, since they are able to bind to membrane ergosterol, forming a tannin-ergosterol complex and, consequently, reducing the amount of ergosterol in Candida cells (Carvalho et al., 2018).

Finally, it is worth pointing out that only in vitro tests were used in the present study. Further pre-clinical in vivo and clinical studies ought to be carried out in order to obtain a better understanding of the mechanisms of action of C. leptophloeos and to validate its efficacy and safety for the treatment of fungal infections.

\section{CONCLUSION}

The present study reported the presence of B-type oligomeric procyanidins in the stem bark of C. leptophloeos, as well as the antifungal and antibiofilm activities of the plant extract against Candida spp. This is the first report of its kind in the literature. BDP, which was isolated for the first time in C. leptophloeos, showed higher anti-Candida activity compared to HELC and FB, with lower MIC and MFC values, as well as greater capacity to reduce biofilm formation. The study showed that the plant extract, $n$-butanol fraction, and the isolated compounds may be used as an alternative complementary mechanism for the treatment of fungal infections, specifically in fluconazole resistant strains and multidrug resistant Candida spp. The results of the study showed that free B-type dimeric procyanidin clearly exhibits fungicidal activity; furthermore, the combined application of BDP with fluconazole leads to the enhancement of the antifungal effect via synergistic action. The study also reported the development and application of a HPLCPDA/ELSD method for direct and simultaneous detection and quantification of five B-type oligomeric procyanidins in the extract of C. leptophloeos. Based on the findings of the study, the HPLC-PDA/ELSD method can be applied as an important tool for the quality control of raw materials and/or herbal medicine, given that C. leptophloeos is widely used as a medicinal plant in Brazil. BDP was found to be responsible, at least in part, for the pharmacological effect observed in C. leptophloeos and can be employed as an analytical marker for the plant species. The findings of the study confirm the antifungal properties and low cytotoxic effects of $C$. leptophloeos, thus providing scientific support for its use in folk medicine toward the treatment of fungal infections.

\section{DATA AVAILABILITY STATEMENT}

The original contributions presented in the study are included in the article/Supplementary Material, further inquiries can be directed to the corresponding author/s.

\section{AUTHOR CONTRIBUTIONS}

RD-M was responsible for conceptualization, methodology, investigation, design of the experiments, and the writing of the original draft. AZ and WV conducted the qualitative and quantitative phytochemical analyses. LS performed antifungal and antibiofilm experiments. JF, SM, and RG conducted isolation and structural elucidation experiments. BA-C and MF-P performed the cytotoxicity tests. MT-R was responsible for the processing of the statistical data. TA was responsible for collecting, drying, and the botanical identification of the plant material. GC was responsible for conceptualization, supervision, writing review of the manuscript. SZ was responsible for conceptualization, methodology, investigation, writing review, supervision, project administration, and funding acquisition. All authors contributed equally toward the elaboration of the manuscript and have given their approval of the final version.

\section{FUNDING}

The research was funded by the Brazilian research funding agencies: Conselho Nacional de Desenvolvimento Científico e Tecnológico $(\mathrm{CNPq})$ and Coordenação de Aperfeiçoamento de Pessoal de Nível Superior (CAPES). RD-M received a Master's scholarship of the CAPES (Grant No. 1729966). GC is a research productivity fellow of the CNPq (Grant No. 313698/2018-0).

\section{ACKNOWLEDGMENTS}

We are grateful to the Conselho de Administração de Pessoal de Ensino Superior (CAPES) for the $\mathrm{PhD}$ scholarship and to the Federal University of Rio Grande do Norte for the financial aid granted in support of the internship at the Paris Descartes University.

\section{SUPPLEMENTARY MATERIAL}

The Supplementary Material for this article can be found online at: https://www.frontiersin.org/articles/10.3389/fmicb.2021. 613155/full\#supplementary-material 


\section{REFERENCES}

Agra, M. F., Baracho, G. S., Nurit, K., Basílio, I. J. L. D., and Coelho, V. P. M. (2007). Medicinal and poisonous diversity of the flora of "Cariri Paraibano", Brazil. J. Ethnopharmacol. 111, 383-395. doi: 10.1016/j.jep.2006.12.007

Amorim-Carmo, B., Daniele-Silva, A., Parente, A. M. S., Furtado, A. A., Carvalho, E., Oliveira, J. W. F., et al. (2019). Potent and broad-spectrum antimicrobial activity of analogs from the scorpion peptide stigmurin. Int. J. Mol. Sci. 20, 1-21. doi: 10.3390/ijms20030623

Anvisa (2017). RESOLUÇÃO RDC No 166, DE 24 DE JULHO DE 2017 - Imprensa Nacional. Available online at: https://www.in.gov.br/materia/-/asset_publisher/ Kujrw0TZC2Mb/content/id/19194581/do1-2017-07-25-resolucao-rdc-n166-de-24-de-julho-de-2017-19194412 (accessed september 29, 2020).

Aslani, N., Hedayati, M. T., Nabili, M., Faramarzi, A., Sadeghi, F., and Moazeni, M. (2018). In vitro interactions of crocin with fluconazole against Candida isolates. Curr. Med. Mycol. 4, 25-30. doi: 10.18502/cmm.4.4.383

Attard, E. (2013). A rapid microtitre plate Folin-Ciocalteu method for the assessment of polyphenols. Open Life Sci. 8, 48-53. doi: 10.2478/s11535-0120107-3

Azzam, S. Z., Cayme, G. J., and Martinez, L. R. (2020). Polymicrobial interactions involving fungi and their importance for the environment and in human disease. Microb. Pathog. 140:103942. doi: 10.1016/j.micpath.2019.103942

Banerjee, M., Lazzell, A. L., Romo, J. A., Lopez-Ribot, J. L., and Kadosh, D. (2019). Filamentation is associated with reduced pathogenicity of multiple non- albicans Candida Species. mSphere 4:e00656-19. doi: 10.1128/msphere. 00656-19

Biasi-Garbin, R. P., Demitto, F., de, O., do Amaral, R. C. R., Ferreira, M. R. A., Soares, L. A. L., et al. (2016). Antifungal potential of plant species from brazilian caatinga against dermatophytes. Rev. Inst. Med. Trop. Sao Paulo 58, 18-22. doi: 10.1590/S1678-9946201658018

Biswal, M., Rudramurthy, S. M., Jain, N., Shamanth, A. S., Sharma, D., Jain, K., et al. (2017). Controlling a possible outbreak of Candida auris infection: lessons learnt from multiple interventions. J. Hosp. Infect. 97, 363-370. doi: 10.1016/j. jhin.2017.09.009

Bonifácio, B. V., Vila, T. V. M., Masiero, I. F., da Silva, P. B., da Silva, I. C., de Oliveira Lopes, É, et al. (2019). Antifungal activity of a hydroethanolic extract from astronium urundeuva leaves against Candida albicans and Candida glabrata. Front. Microbiol. 10:2642. doi: 10.3389/fmicb.2019.02642

Campoy, S., and Adrio, J. L. (2017). Antifungals. Biochem. Pharmacol. 133, 86-96. doi: 10.1016/j.bcp.2016.11.019

Cartaxo, S. L., de Almeida Souza, M. M., and de Albuquerque, U. P. (2010). Medicinal plants with bioprospecting potential used in semi-arid northeastern Brazil. J. Ethnopharmacol. 131, 326-342. doi: 10.1016/j.jep.2010.07.003

Carvalho, R. S., Carollo, C. A., Magalhães, J. C., Palumbo, J. M. C., Boaretto, A. G., Nunes e Sá, I. C., et al. (2018). Antibacterial and antifungal activities of phenolic compound-enriched ethyl acatate fraction from Cochlosperrmum regium (mart. E. Schr. Pilger roots: Mechanisms of action and synergism with tannin and gallic acid. South African J. Bot. 114, 181-187. doi: 10.1016/j.sajb.2017.11.010

Chaves, G. M., Diniz, M. G., da Silva-Rocha, W. P., de Souza, L. B. F. C., Gondim, L. A. M., Ferreira, M. A. F., et al. (2013). Species distribution and virulence factors of Candida spp. isolated from the oral cavity of kidney transplant recipients in Brazil. Mycopathologia 175, 255-263. doi: 10.1007/s11046-0139640-5

Chaves, T. P., Santos, J. S., Delcio, C. F., Medeiros, A. C. D., Silva, H., and Clementino, E. L. C. (2016). Avaliação de atividades biológicas dos extratos de Commiphora leptophloeos (Imburana) (Mart.). J. B. Gillet. Rev. Cuba. Plantas Med. 21, 1-10.

CLSI (2008). M27-A3 Reference Method for Broth Dilution Antifungal Susceptibility Testing of Yeasts; Approved Standard-Third Edition. Available online at: www.clsi.org (accessed September 29, 2020).

CLSI (2017). Performance Standards for Antifungal Susceptibility Testing of Yeasts, 1st Edn. CLSI supplement M60. Wayne, PA: Clinical and Laboratory Standards Institute.

Colombo, A. L., Júnior, J. N. D. A., and Guinea, J. (2017). Emerging multidrugresistant Candida species. Curr. Opin. Infect. Dis. 30, 528-538. doi: 10.1097/ QCO.0000000000000411

Czerwińska, M. E., Dudek, M. K., Pawłowska, K. A., Pruś, A., Ziaja, M., and Granica, S. (2018). The influence of procyanidins isolated from small-leaved lime flowers (Tilia cordata Mill.) on human neutrophils. Fitoterapia 127, 115122. doi: 10.1016/j.fitote.2018.02.018

Da Silva, I. F., Guimarães, A. L., Amorim, V. S., Da Silva, T. M. G., De Moraes Peixoto, R., Nunes, X. P., et al. (2019). Antimicrobial activity of ethanolic extracts from Commiphora leptophloeos (mart.) J. B. Gillett against Staphylococcus spp. isolated from cases of mastitis in ruminants. Cienc. Anim. Bras. 20, 1-14. doi: 10.1590/1089-6891v20e-57228

Da Silva, R. C. S., Milet-Pinheiro, P., Da Silva, P. C. B., Da Silva, A. G., Da Silva, M. V., Do Amaral Ferraz Navarro, D. M., et al. (2015). (E)Caryophyllene and $\alpha$-humulene: aedes aegypti oviposition deterrents elucidated by gas chromatography-electrophysiological assay of Commiphora leptophloeos leaf oil. PLoS One 10:e0144586. doi: 10.1371/journal.pone.0144586

Dantas-Medeiros, R., Furtado, A. A., Zanatta, A. C., Torres-Rêgo, M., Guimarães Lourenço, E. M., Ferreira Alves, J. S., et al. (2021). Mass spectrometry characterization of Commiphora leptophloeos leaf extract and preclinical evaluation of toxicity and anti-inflammatory potential effect. J. Ethnopharmacol. 264:113229. doi: 10.1016/j.jep.2020.113229

De Cássia Orlandi Sardi, J., Silva, D. R., Soares Mendes-Giannini, M. J., and Rosalen, P. L. (2018). Candida auris: epidemiology, risk factors, virulence, resistance, and therapeutic options. Microb. Pathog. 125, 116-121. doi: 10.1016/ j.micpath.2018.09.014

De Oliveira, G. T., Ferreira, J. M. S., Rosa, L. H., de Siqueira, E. P., Johann, S., Lima, L. A. R., et al. (2014). In vitro antifungal activities of leaf extracts of Lippia alba (Verbenaceae) against clinically important yeast species. Rev. Soc. Bras. Med. Trop. 47, 247-250. doi: 10.1590/0037-8682-0008-2013

Deorukhkar, S. C., and Saini, S. (2016). Why Candida species have emerged as important nosocomial pathogens? Int. J. Curr. Microbiol. App. Sci. 5, 533-545. doi: 10.20546/ijcmas.2016.501.054

Diba, K., Makhdoomi, K., Nasri, E., Vaezi, A., Javidnia, J., Gharabagh, D. J., et al. (2018). Emerging Candida species isolated from renal transplant recipients: species distribution and susceptibility profiles. Microb. Pathog. 125, 240-245. doi: 10.1016/j.micpath.2018.09.026

Fakhim, H., Emami, S., Vaezi, A., Hashemi, S. M., Faeli, L., Diba, K., et al. (2017). In vitro activities of novel azole compounds ATTAF-1 and ATTAF-2 against fluconazole-susceptible and-resistant isolates of Candida species. Antimicrob. Agents Chemother. 61:e1106-16. doi: 10.1128/AAC.01106-16

Fakhim, H., Vaezi, A., Javidnia, J., Nasri, E., Mahdi, D., Diba, K., et al. (2020). Candida africana vulvovaginitis: prevalence and geographical distribution. J. Mycol. Med. 30:100966. doi: 10.1016/j.mycmed.2020.100966

Fuentefria, A. M., Pippi, B., Dalla Lana, D. F., Donato, K. K., and de Andrade, S. F. (2018). Antifungals discovery: an insight into new strategies to combat antifungal resistance. Lett. Appl. Microbiol. 66, 2-13. doi: 10.1111/lam.12820

Herrera, C. L., Alvear, M., Barrientos, L., Montenegro, G., and Salazar, L. A. (2010). The antifungal effect of six commercial extracts of Chilean propolis on Candida spp. Cienc. e Investig. Agrar. 37, 75-84. doi: 10.4067/S0718-16202010000100007

Hopmann, E., Frey, A., and Minceva, M. (2012). A priori selection of the mobile and stationary phase in centrifugal partition chromatography and countercurrent chromatography. J. Chromatogr. A 1238, 68-76. doi: 10.1016/j.chroma. 2012.03.035

Jiang, Y., Zhang, H., Qi, X., and Wu, G. (2020). Structural characterization and antioxidant activity of condensed tannins fractionated from sorghum grain. J. Cereal Sci. 92, 102918. doi: 10.1016/j.jcs.2020.102918

Kaur, H., and Chakrabarti, A. (2017). Strategies to reduce mortality in adult and neonatal candidemia in developing countries. J. Fungi 3:41. doi: 10.3390/ jof3030041

Li, D. D., Chai, D., Huang, X. W., Guan, S. X., Du, J., Zhang, H. Y., et al. (2017). Potent in vitro synergism of fluconazole and osthole against fluconazoleresistant Candida albicans. Antimicrob. Agents Chemother. 61:e00436-17. doi: 10.1128/AAC.00436-17

Lima, C. S., Santos, H. R. S., de Albuquerque, U. P., and da Silva, F. S. B. (2017). Mycorrhizal symbiosis increase the level of total foliar phenols and tannins in Commiphora leptophloeos (Mart.) J.B. Gillett seedlings. Ind. Crops Prod. 104, 28-32. doi: 10.1016/j.indcrop.2017.04.020

Macáková, K., Kolečkář, V., Cahlíková, L., Chlebek, J., Hoštálková, A., Kuča, K., et al. (2014). Tannins and their influence on health. Recent Adv. Med. Chem. 1, 159-208. doi: 10.1016/B978-0-12-803961-8.50006-3

Macedo, J. G. F., Menezes, I. R. A., Ribeiro, D. A., Santos, M. O., Mâcedo, D. G., Macêdo, M. J. F., et al. (2018). Analysis of the variability of therapeutic 
indications of medicinal species in the northeast of Brazil: comparative study. Evid. Based Complement. Altern. Med. 2018:6769193. doi: 10.1155/2018/ 6769193

Mahmoudi, Y., Badali, H., Hashemi, S. M., Ansari, M., Fakhim, H., Fallah, M., et al. (2019). New potent antifungal triazole alcohols containing N-benzylpiperazine carbodithioate moiety: synthesis, in vitro evaluation and in silico study. Bioorg. Chem. 90:103060. doi: 10.1016/j.bioorg.2019.103060

Melo, A. S., Bizerra, F. C., Freymüller, E., Arthington-Skaggs, B. A., and Colombo, A. L. (2011). Biofilm production and evaluation of antifungal susceptibility amongst clinical Candida spp. isolates, including strains of the Candida parapsilosis complex. Med. Mycol. 49, 253-262. doi: 10.3109/13693786.2010. 530032

Melo, J. G., Rodrigues, M. D., Nascimento, S. C., Amorim, E. L. C., and Albuquerque, U. P. (2017). Cytotoxicity of plants from the Brazilian semi-arid region: a comparison of different selection approaches. South African J. Bot. 113, 47-53. doi: 10.1016/j.sajb.2017.07.013

Ming, D. S., López, A., Hillhouse, B. J., French, C. J., Hudson, J. B., and Towers, G. H. N. (2002). Bioactive constituents from Iryanthera megistophylla. J. Nat. Prod. 65, 1412-1416. doi: 10.1021/np020169l

Morais-Braga, M. F. B., Sales, D. L., Carneiro, J. N. P., Machado, A. J. T., dos Santos, A. T. L., de Freitas, M. A., et al. (2016). Psidium guajava L. and Psidium brownianum Mart ex DC.: chemical composition and anti - Candida effect in association with fluconazole. Microb. Pathog. 95, 200-207. doi: 10.1016/j. micpath.2016.04.013

Motahari, K., Badali, H., Hashemi, S. M., Fakhim, H., Mirzaei, H., Vaezi, A., et al. (2018). Discovery of benzylthio analogs of fluconazole as potent antifungal agents. Future Med. Chem. 10, 987-1002. doi: 10.4155/fmc-2017-0295

Nett, J. E. (2019). Candida auris: an emerging pathogen "incognito"? PLoS Pathog. 15:e1007638. doi: 10.1371/journal.ppat.1007638

Pereira, J. J. D. S., de Pereira, A. P. C., Jandú, J. J. B., da Paz, J. A., Crovella, S., do Correia, M. T. S., et al. (2017). Commiphora leptophloeos phytochemical and antimicrobial characterization. Front. Microbiol. 8:52. doi: 10.3389/fmicb.2017. 00052

Rauf, A., Imran, M., Abu-Izneid, T., Iahtisham-Ul-Haq, Patel, S., Pan, X., et al. (2019). Proanthocyanidins: a comprehensive review. Biomed. Pharmacother. 116:108999. doi: 10.1016/j.biopha.2019.108999

Robbins, N., Caplan, T., and Cowen, L. E. (2017). Molecular evolution of antifungal drug resistance. Annu. Rev. Microbiol. 71, 753-775. doi: 10.1146/annurevmicro-030117-020345

Rohr, G. E., Meier, B., and Sticher, O. (2000). Analysis of procyanidins. Stud. Nat. Prod. Chem. 21, 497-570. doi: 10.1016/S1572-5995(00)80013-7

Salazar-Aranda, R., Granados-Guzmán, G., Pérez-Meseguer, J., González, G. M., and De Torres, N. W. (2015). Activity of polyphenolic compounds against Candida glabrata. Molecules 20, 17903-17912. doi: 10.3390/molecules201017903

Sardi, J. C. O., Scorzoni, L., Bernardi, T., Fusco-Almeida, A. M., and Mendes Giannini, M. J. S. (2013). Candida species: current epidemiology, pathogenicity, biofilm formation, natural antifungal products and new therapeutic options. J. Med. Microbiol. 62, 10-24. doi: 10.1099/jmm.0. 045054-0

Shen, T., Li, G. H., Wang, X. N., and Lou, H. X. (2012). The genus Commiphora: a review of its traditional uses, phytochemistry and pharmacology. J. Ethnopharmacol. 142, 319-330. doi: 10.1016/j.jep.2012. 05.025

Sherry, L., Ramage, G., Kean, R., Borman, A., Johnson, E. M., and Richardson, M. D. (2017). Biofilm-forming capability of highly virulent. Emerg. Infect. Dis. 23, 328-331. doi: 10.3201/eid2302.161320

Shoji, T., Mutsuga, M., Nakamura, T., Kanda, T., Akiyama, H., and Goda, Y. (2003). Isolation and structural elucidation of some procyanidins from apple by lowtemperature nuclear magnetic resonance. J. Agric. Food Chem. 51, 3806-3813. doi: 10.1021/jf0300184

Silva-Rocha, W. P., de Azevedo, M. F., Ferreira, M. R. A., da Silva, J., de, F., Svidzinski, T. I. E., et al. (2017). Effect of the ethyl acetate fraction of Eugenia uniflora on proteins global expression during morphogenesis in Candida albicans. Front. Microbiol. 8:1788. doi: 10.3389/fmicb.2017.01788
Singh, J. (2015). International conference on harmonization of technical requirements for registration of pharmaceuticals for human use. J. Pharmacol. Pharmacother. 6:185. doi: 10.4103/0976-500X.162004

Souza, L. B. F. C., Silva-Rocha, W. P., Ferreira, M. R. A., Soares, L. A. L., Svidzinski, T. I. E., Milan, E. P., et al. (2018). Influence of eugenia uniflora extract on adhesion to human buccal epithelial cells, biofilm formation, and cell surface hydrophobicity of Candida spp. from the oral cavity of kidney transplant recipients. Molecules 23:2418. doi: 10.3390/molecules231 02418

Spivak, E. S., and Hanson, K. E. (2018). Candida auris: an emerging fungal pathogen. J. Clin. Microbiol. 56:e01588-17. doi: 10.1128/JCM.01588-17

Stepanović, S., Vuković, D., Hola, V., Di Bonaventura, G., Djukić, S., Ćirković, I., et al. (2007). Quantification of biofilm in microtiter plates: overview of testing conditions and practical recommendations for assessment of biofilm production by staphylococci. Apmis 115, 891-899. doi: 10.1111/j.1600-0463. 2007.apm_630.x

Tanaka, T., Matsuo, Y., and Saito, Y. (2018). Solubility of tannins and preparation of oil-soluble derivatives. J. Oleo Sci. 67, 1179-1187. doi: 10.5650/jos.ess 18164

Tocci, N., Weil, T., Perenzoni, D., Narduzzi, L., Madriñán, S., Crockett, S., et al. (2018). Phenolic profile, chemical relationship and antifungal activity of Andean Hypericum species. Ind. Crops Prod. 112, 32-37. doi: 10.1016/j.indcrop. 2017.10.030

Trentin, D. D. S., Giordani, R. B., Zimmer, K. R., Da Silva, A. G., Da Silva, M. V., Correia, M. T. D. S., et al. (2011). Potential of medicinal plants from the Brazilian semi-arid region (Caatinga) against Staphylococcus epidermidis planktonic and biofilm lifestyles. J. Ethnopharmacol. 137, 327-335. doi: 10.1016/ j.jep.2011.05.030

Trentin, D. S., Silva, D. B., Amaral, M. W., Zimmer, K. R., Silva, M. V., Lopes, N. P., et al. (2013). Tannins possessing bacteriostatic effect impair Pseudomonas aeruginosa adhesion and biofilm formation. PLoS One 8:e0066257. doi: 10.1371/ journal.pone.0066257

Trolezi, R., Azanha, J. M., Paschoal, N. R., Chechi, J. L., Dias Silva, M. J., Fabris, V. E., et al. (2017). Stryphnodendron adstringens and purified tannin on Pythium insidiosum: in vitro and in vivo studies. Ann. Clin. Microbiol. Antimicrob. 16, 1-7. doi: 10.1186/s12941-017-0183-3

Vidal-Gutiérrez, M., Robles-Zepeda, R. E., Vilegas, W., Gonzalez-Aguilar, G. A., Torres-Moreno, H., and López-Romero, J. C. (2020). Phenolic composition and antioxidant activity of Bursera microphylla A. Gray. Ind. Crops Prod. 152:112412. doi: 10.1016/j.indcrop.2020.112412

Zambuzzi-Carvalho, P. F., Tomazett, P. K., Santos, S. C., Ferri, P. H., Borges, C. L., Martins, W. S., et al. (2013). Transcriptional profile of Paracoccidioides induced by oenothein B, a potential antifungal agent from the Brazilian Cerrado plant Eugenia uniflora Hirotada Mori. BMC Microbiol. 13:227. doi: 10.1186/14712180-13-227

Zelante, T., Costantini, C., and Romani, L. (2020). Microbiome-mediated regulation of anti-fungal immunity. Curr. Opin. Microbiol. 58, 8-14. doi: 10. 1016/j.mib.2020.05.002

Zhang, Y., Xiong, H., Xu, X., Xue, X., Liu, M., Xu, S., et al. (2018). Compounds identification in semen cuscutae by ultra-high-performance liquid chromatography (UPLCs) coupled to electrospray ionization mass spectrometry. Molecules 23:1199. doi: 10.3390/molecules23051199

Conflict of Interest: The authors declare that the research was conducted in the absence of any commercial or financial relationships that could be construed as a potential conflict of interest.

Copyright (c) 2021 Dantas-Medeiros, Zanatta, de Souza, Fernandes, Amorim-Carmo, Torres-Rêgo, Fernandes-Pedrosa, Vilegas, Araújo, Michel, Grougnet, Chaves and Zucolotto. This is an open-access article distributed under the terms of the Creative Commons Attribution License (CC BY). The use, distribution or reproduction in other forums is permitted, provided the original author(s) and the copyright owner(s) are credited and that the original publication in this journal is cited, in accordance with accepted academic practice. No use, distribution or reproduction is permitted which does not comply with these terms. 